Professor Dr. Volker Haas*

\title{
Zur Notwendigkeit einer Reform der Tötungsdelikte. Zugleich eine kritische Würdigung des Abschlussberichts der Expertengruppe
}

\section{Einleitung}

Über die Notwendigkeit einer Neugestaltung der Tötungsdelikte (§§ 211-213, 57a StGB) herrscht nahezu Einigkeit. Schon der 53. Deutsche Juristentag hat 1980 ihre Reformbedürftigkeit festgestellt ${ }^{1}$, ohne dass der Gesetzgeber Anlass gesehen hätte, aus dieser Diagnose Konsequenzen zu ziehen. Auch die Bundesregierung und der Bundesrat haben in der 13. Legislaturperiode anerkannt, dass die Tötungsdelikte reformiert werden müssen ${ }^{2}$. Geschehen ist seitdem gleichwohl nichts. Nunmehr hat es sich bekanntlich Justizminister Maas in dieser Legislaturperiode zur Aufgabe gemacht, das Strafgesetz zu novellieren. Der offizielle Abschlussbericht der eingesetzten Expertengruppe zur Reform der Tötungsdelikte ist im Juni letzten Jahres vorgelegt und sodann im Folgemonat der Öffentlichkeit vorgestellt worden. Die sehr divergierenden Vorstellungen der Kommissionsmitglieder über die Neugestaltung der §§ 211-213, 57 a StGB bestätigen die allgemeine Einschätzung: So unumstritten es ist, dass die Tötungsdelikte einer Reform bedürfen, so umstritten ist es, wie diese Reform auszugestalten ist. Die Expertengruppe hat wohl auch aus diesem Grund darauf verzichtet, einen konkreten Regelungsentwurf vorzulegen, sondern ihre Empfehlungen in Form einzelner Beschlussfassungen ausgesprochen ${ }^{3}$. Im Grundsatz hat sich die Expertengruppe mit jeweils absoluter Mehrheit für die Einführung eines Qualifikationsmodells mit

1 Deutscher Juristentag, Sitzungsbericht, 1980, M 150.

2 BT-Drucks. 13/4830 S. 7; BT-Drucks. 13/8587 S. 55, 78.

3 So auch die Einschätzung von Momsen, StV 2015, Heft 12, Editorial, S. I.

*Kontaktperson: Volker Haas, Inhaber eines Lehrstuhls für Strafrecht und Strafprozessrecht an der Ruprecht-Karls-Universität Heidelberg. 
der vorsätzlichen Tötung als Grundtatbestand entschieden. Neben dem Grundtatbestand der vorsätzlichen Tötung soll eine gesetzliche Regelung für höchststrafwürdige Tötungen eingeführt werden: der Mord als Qualifikationstatbestand. Beide Tatbestände sollen also zueinander in einem Stufenverhältnis stehen. Dem Regelbeispielmodell wurde eine Absage erteilt ${ }^{4}$. Dem Totschlag als Grundtatbestand soll ein minder schwerer Fall des Totschlags zur Seite gestellt werden ${ }^{5}$. Die Expertengruppe weicht damit von den Beschlussfassungen des 53. Deutschen Juristentags ab. Damals hat nur eine kleine Minderheit für die Beibehaltung des traditionellen dreistufigen Regelmodells votiert ${ }^{6}$.

Zweck des nachfolgenden Beitrags ist es, die wesentlichen Beschlüsse der Expertengruppe vorzustellen und im Dialog mit dem eigenen Standpunkt einer kritischen Würdigung zu unterziehen ${ }^{7}$. Schon aus Platzmangel ist es dabei leider nicht möglich, die große Zahl sonstiger Reformvorschläge zu berücksichtigen ${ }^{8}$. Dies gilt ebenso für die Rechtsvergleichung, obwohl gerade diese bei Reformprojekten ihren größten Nutzen entfaltet und eigentlich ein unentbehrliches Instrument ist, um Anstöße für mögliche Regelungsalternativen zu gewinnen. Die Untersuchung gliedert sich wie folgt: Im nächsten Abschnitt (II.), der den Schwerpunkt des Beitrags bildet, werden die Gründe für die Notwendigkeit einer Reform umfassend dargelegt und mit den Empfehlungen der Expertengruppe abgeglichen. Im anschließenden Abschnitt (III.) wird das Privilegierungsmodell thematisiert. Der Beitrag endet mit einer Schlussbemerkung, in der ein Resümee gezogen wird (IV.).

4 Beratungsergebnisse, in: Abschlussbericht der Expertengruppe zur Reform der Tötungsdelikte (§§ 211 - 213, 57a StGB), 2015, S. $24 \mathrm{ff}$.

5 Beratungsergebnisse, in: Abschlussbericht (Anm. 4), S. $62 \mathrm{f}$.

6 Deutscher Juristentag, Sitzungsbericht (Anm. 1), M 151, 155, 163.

7 Einen kurzen und prägnanten Überblick gibt Dölling, DRiZ 2015, $260 \mathrm{ff}$.

8 Vgl. die Übersicht über die bisherigen Reformvorschläge, in: Abschlussbericht (Anm. 4),

S. $193 \mathrm{ff}$;; siehe auch Eser, Festschrift für Kargl, 2015, S. $91 \mathrm{ff}$. 


\section{Gründe für den Reformbedarf der Tötungsdelikte}

\section{Der historische Hintergrund des heutigen Mordtatbestandes}

\section{a) Die Abschaffung des Prämeditationskonzepts durch den nationalsozialistischen Gesetzgeber}

Die gegenwärtige Regelung der Tötungsdelikte geht bekanntlich auf das Gesetz zur Änderung des Reichsstrafgesetzbuchs vom 4. September 1941 zurück ${ }^{9}$. Nach dem Zweiten Weltkrieg wurde zunächst lediglich die Todesstrafe durch Art. 102 GG abgeschafft. Art. 1 Nr. 1 c des Dritten Strafrechtsänderungsgesetzes vom 4. August 1953 ersetzte diese daher durch lebenslanges Zuchthaus und strich den dritten Absatz, der in besonderen Ausnahmefällen die Verhängung von lebenslangem Zuchthaus vorsah. Zugleich wurde die Bestrafung des Totschlags neu geregelt. Durch Art. 4 und Art. 5 des Ersten Gesetzes zur Reform des Strafrechts vom 25. Juni 1969 wurde schließlich auch das Zuchthaus abgeschafft und durch Gefängnisstrafe ersetzt. Die §§ 211 Abs. 1, 212 StGB erhielten dadurch ihre derzeit noch geltende Fassung.

Das Gesetz zur Änderung des Reichsstrafgesetzbuchs vom 4. September 1941 bildete schon deswegen eine einschneidende Zäsur, weil es die auf dem Prämeditationskonzept beruhende Regelung des Reichsstrafgesetzbuchs von 1871 verwarf, die allerdings nicht die Tötung mit Vorbedacht für das Vorliegen eines Mordes als maßgeblich erachtete, sondern die Ausführung der Tat mit Überlegung. Anfang des 20. Jahrhunderts wuchs die Zahl der Strafrechtswissenschaftler, die die Konzeption des Reichsstrafgesetzbuchs kritisierten ${ }^{10}$. Trotz des Wortlauts des § 211 RStGB war umstritten, welcher Zeitpunkt für die erforderliche Überlegung maßgeblich sein sollte. Des Weiteren war umstritten, ob die Überlegung das „Ob“ oder das „Wie“ der Tatbegehung betreffen sollte. Vor allem wurde moniert, dass durch die ausschließliche Anknüpfung an das Kriterium der Überlegung sonstige strafmildernde Umstände keine Berücksichtigung finden konnten. Ungeachtet dessen wurde in den meisten Reformentwürfen bis Anfang der dreißiger Jahre das Überlegungskonzept fortgeführt ${ }^{11}$. Angesichts der Kritik an dem Prämeditationskonzept fiel es dem nationalsozialistischen Gesetzgeber bzw.

9 RGBl.IS. 549.

10 Umfassende Darstellung bei Linka, Mord und Totschlag, 2008, S. $67 \mathrm{ff}$.

11 Nachweise bei Linka (Anm. 10), S. $97 \mathrm{ff}$. 
der von ihm eingesetzten Strafrechtskommission leicht, sich von der Gleichsetzung des Mordes mit der Tötung aus Überlegung zu verabschieden und ein völlig neues Konzept einzuführen.

\section{b) Die Tätertypenlehre und die Doktrin des Willensstrafrechts als ideologischer Hintergrund des Änderungsgesetzes von 1941}

\section{aa) Der Einfluss beider Lehren auf die Gesetzgebung}

Kaum zu bezweifeln ist, dass sich die damalige Strafrechtskommission an dem aus dem Jahre 1894 stammenden Vorentwurf von Stooß zum Schweizer Strafgesetzbuch orientiert hat, der die germanische Rechtstradition der unehrlichen, gemeinen Tötung wieder aufzugreifen suchte ${ }^{12}$. Die Gegenüberstellung zwischen dem Mörder und dem Totschläger im Wortlaut der neu gefassten $\S \S 211,212$ RStGB, die sich bei Stoo $\beta$ bezeichnenderweise nicht findet ${ }^{13}$, deutet jedoch darauf hin, dass die Tätertypenlehre in das Gesetz Eingang gefunden hat ${ }^{14}$. Bestätigt wird diese Vermutung durch die Gesetzgebungsmaterialien. Schon im Arbeitsbericht zum Entwurf der ersten Lesung aus dem Jahre 1935 äußerte das Mitglied der Strafrechtskommission Gleispach, dass der Gesetzgebungsvorschlag von der Tat ausgehe und bei der Bewertung des Täters ende. Der Mörder und - wenn auch weniger ausgeprägt - der Totschläger seien in der Vorstellungswelt lebendige Typen $^{15}$. Während der zweiten Lesung behauptete der damalige Reichsjustizminister Gürtner, dass nicht die Tat, sondern die Person des Täters qualifiziert werde $^{16}$. Gleispach hielt in seinem Arbeitsbericht von 1936 der aus der zweiten Lesung hervorgehenden neuen Fassung vom Februar desselben Jahres zugute, deutlicher zum Ausdruck zu bringen, dass stets eine Gesamtbewertung des Täters stattzufinden habe und dass erst ihr Ergebnis zum Urteil „Mörder“ führe ${ }^{17}$. Die Überprüfung der Beschlüsse der zweiten Lesung durch eine Unterkommission führte noch im selben Jahr zu einer weiteren Änderung durch den „Entwurf eines deutschen Strafgesetzbuches“ vom Dezember 1936, der unter anderem beim

12 Thomas, Die Geschichte des Mordparagraphen - eine normgenetische Untersuchung bis in die Gegenwart, 1985, S. $242 \mathrm{ff}$.

13 Stooß, Schweizerisches Strafgesetzbuch. Vorentwurf mit Motiven im Auftrage des Schweizerischen Bundesrates, 1894, S. 147.

14 Müssig, Mord und Totschlag, 2005, S. 80; vgl. auch die Darstellung bei Beck, ZIS 2016, 10, $12 \mathrm{f}$.

15 Gleispach, in: Gürtner (Hrsg.), Das kommende deutsche Strafrecht, Besonderer Teil, 2. Aufl. 1935, S. $256 \mathrm{f}$.

16 Schubert/Regge (Hrsg.), Quellen zur Reform des Straf- und Strafprozeßrechts, Band 2, 4. Teil, 1994, S. 162.

17 Gleispach, in: Gürtner (Hrsg.) (Anm. 15), S. 385. 
Mordtatbestand auf die Regelbeispielstechnik der Vorentwürfe verzichtete. In den Vorbemerkungen zu diesem Entwurf heißt es, dass einzelne Tatbestände durch die Aufstellung von Tätertypen wie beispielsweise den Mörder sittlich ausgerichtet seien. Hierbei handele es sich nicht nur um eine Frage der technischen Ausgestaltung der Tatbestände oder um eine veränderte Wortfassung. Der an Tätertypen angelehnte Tatbestand enthalte vielmehr dadurch eine besondere subjektive Betonung, durch die eine ganz bestimmte Persönlichkeitsvorstellung in dem Richter geweckt werde ${ }^{18}$. Des Weiteren wird in der Begründung zu den Tötungsdelikten ausgeführt, dass der Entwurf die Unterscheidung zwischen Mord und Totschlag in Anlehnung an die im Volk lebendigen Rechtsvorstellungen nach dem Grad der Verwerflichkeit der Tätergesinnung getroffen habe. Der Entwurf verwende nicht wie das geltende Recht die Bezeichnungen „Mord“ und „Totschlag“, sondern charakterisiere den Täter als „Mörder“ oder „Totschläger“. Hiermit weise der Entwurf den Richter auf die Aufgabe hin, zur Beurteilung der Tat vor allem die Gesamtpersönlichkeit des Täters zu prüfen und zu würdigen. Die Begründung unterstellt dabei, dass das Rechtsbewusstsein des Volkes bei der Unterscheidung zwischen Mord und Totschlag sittlichen Erwägungen den Vorrang einräumt ${ }^{19}$.

Die zwischenzeitlich stockenden Reformbestrebungen erhielten erst im Rahmen der Kriegsstrafgesetzgebung Ende der dreißiger Jahre wieder neuen Schwung. Die Novellierung des Reichsstrafgesetzbuchs durch die Schwerverbrecherverordnung von 1940, durch die der Anwendungsbereich der Todesstrafe erweitert werden sollte, scheiterte zwar. Ihre Grundlage war der Entwurf eines Deutschen Strafgesetzbuchs vom Dezember 1936, der die Neuregelung der Tötungsdelikte in Form der $\S \S 405$ bis 407 enthielt. Ihre Erwähnung ist aber deswegen von Interesse, weil die Begründung der Schwerverbrecherverordnung sachlich die Erläuterungen des Entwurfs aufgriff. So wurde hervorgehoben, dass für die Unterscheidung von Mord und Totschlag die Gesinnung, aus der heraus der Täter die Tötung vorgenommen oder die er durch die Art der Ausführung der Tat und die gewählten Mittel bewiesen hat, entscheidend sein müsse und dass die Bezeichnung des Täters als Mörder bzw. als Totschläger den Richter darauf hinweise, die Gesamtpersönlichkeit des Täters zu prüfen und zu würdigen ${ }^{20}$. Die amtliche Begründung zu § 2 des Strafrechtsänderungsgesetzes selbst ist unergiebig.

Dass ungeachtet dessen an der durch die Kommission erarbeiteten strafrechtsideologischen Richtschnur festgehalten wurde, bestätigt die wenige Mo-

18 Schubert/Regge (Anm. 16), S. 3.

19 Schubert/Regge (Anm. 16), S. $245 \mathrm{f}$.

20 BA-R 3001/20856, Blatt 344; zitiert nach Linka (Anm. 10), S. 188 Fn. 157. 
nate später veröffentlichte Kommentierung des Strafrechtsänderungsgesetzes durch das Kommissionsmitglied Freisler. Entsprechend der neuen, auf der Tätertypenlehre aufbauenden strafrechtlichen Anschauung hatte Freisler zufolge der Gesetzgeber nicht die Frage lösen müssen, was ein Mord, sondern wer ein Mörder sei. Angesichts der absolut angedrohten Todesstrafe habe die Aufgabe darin bestanden, das Täterbild des Mörders richtig zu umgrenzen. Freisler zufolge bestand aber Einigkeit, dass Mord und Totschlag mit Hilfe einer sittlichen Wertung auf der Grundlage gesunden Volksempfindens voneinander abzugrenzen seien. Gemeinsamer Nenner des Mordes sollte die betätigte besonders verwerfliche Gesinnung des Täters sein. Diese charakterisiert den Mörder, der nach Auffassung von Freisler von grundsätzlich anderer Wesensart ist als der Täter eines Totschlags: Der Mörder sei von besonders gemeiner Gesinnungsart. Die Kennzeichnung des Täters als Mörder war laut Freisler auch nach Vorstellung des Gesetzgebers als Anweisung an den Richter zu verstehen, die Erfüllung des Mordtatbestands von einer Gesamtwürdigung des Täters abhängig zu machen $^{21}$.

\section{bb) Der Inhalt der Tätertypenlehre und der Doktrin des Willensstrafrechts (1) Die materiale Dimension der Tätertypenlehre}

Worin bestand die Pointe der Tätertypenlehre? Seinerzeit wurde zwischen einem kriminologischen und einem normativen Tätertypus unterschieden. Mit dem kriminologischen Tätertypus bezeichnete man eine empirisch bzw. naturwissenschaftlich erfassbare Disposition oder ein empirisch bzw. naturwissenschaftlich erfassbares Verhaltensmuster - wie zum Beispiel beim Gewohnheitstäter. Die rechtliche Relevanz der wertfreien Kategorie des kriminologischen Tätertypus wurde jedoch allseits abgelehnt. Es entsprach nicht der Idee der Tätertypenlehre, die Tat (nur) als Symptom der Gefährlichkeit des Täters aufzufassen²2. Demgegenüber sollte das neue nationalsozialistische Strafrecht auf dem von Dahm stammenden Konzept des normativen Tätertypus gründen. Dieses Konzept fußte auf einer „materialen“ und einer „methodischen“ Säule. In materialer Hinsicht forderte es, Tat und Täter als Einheit zu betrachten bzw. den Sinnzusammenhang zwischen beiden zu berücksichtigen und damit dem Umstand Rechnung zu tragen, dass die Tat durch die Gesinnung des Täters geprägt und ins Persönliche

21 Freisler, DJ 1941, 929, $932 \mathrm{ff}$.

22 Dahm, DR 1942, 401, 404; ders., Der Tätertyp im Strafrecht, 1940, S. 187, 189f., 203, 207 f.; vgl. auch ders., in: Dahm et al. (Hrsg.), Grundfragen der neuen Rechtswissenschaft, 1935, S. 62, 88: kein psychologischer Typus; Schaffstein, in: Dahm et al. (Hrsg.), a.a.O., S. 108, 119ff.; ebenso Schmidt/Leichner, DR 1941, 2145, $2147 \mathrm{f}$. 
gehoben werde ${ }^{23}$. Warum wurde dem täterstrafrechtlichen Bezug eine derartige konstitutive Bedeutung für den Verbrechensbegriff beigemessen? Man kommt einer Antwort näher, wenn man sich der Auffassung der Tätertypenlehre bewusst wird, dass der Täter durch die Begehung der Tat seine sittliche Minderwertigkeit zum Ausdruck bring $\mathrm{t}^{24}$ und daher eine ethische Bewertung des Täters erforderlich ist $^{25}$.

\section{(2) Ihre Ergänzung durch die Doktrin des Willensstrafrechts}

Es ist zuzugeben, dass die gesinnungsstrafrechtliche Ausgestaltung des Strafrechts sowie seine auf sittlichen bzw. sozialethischen Bewertungsmaßstäben fußende Ethisierung schon vor der nationalsozialistischen Herrschaft propagiert wurden $^{26}$. Ungeachtet dessen erhielt die Tätertypenlehre in ihrer materialen Dimension erst durch die nationalsozialistische Doktrin des Willensstrafrechts ihr ideologisches Fundament, das die Stoßrichtung der Betonung des täterstrafrechtlichen Elements eigentlich erst verständlich und nachvollziehbar macht. Das Willensstrafrecht zielte auf die Überwindung der ausschließlichen Herrschaft des Rechtsgüterschutzdogmas ab ${ }^{27}$. Für die Strafbarkeit des Täters sollte es der Doktrin des Willensstrafrechts zufolge nicht entscheidend auf den äußeren Vorgang oder Erfolg ankommen. Das Verbrechen bedeute etwas anderes als die Verletzung von Gütern und Interessen ${ }^{28}$. Vielmehr sollte vornehmlich die Betätigung des verbrecherischen Willens bzw. der verwerflichen Gesinnung bestraft werden ${ }^{29}$, weil sich der Täter durch die Betätigung seines bösen Willens zum Feind der Lebensordnung des Volkes mache und daher äußerstenfalls vernichtet werden müsse ${ }^{30}$. Strafrecht sei Kampf an der inneren Front der nationalsozialistischen

23 Dahm, DR 1942, 401, 405; ders. (Anm. 22), S. 187, 206; vgl. auch die Bemerkung von Schaffstein, in: Dahm et al. (Hrsg.) (Anm. 22), S. 108, 122, dass das Bestreben, das Verbrechen als Ausdruck der verbrecherischen Gesinnung des Täters zu begreifen, zwar nicht mit seiner Auffassung des Verbrechens als Pflichtverletzung identisch sei, aber auch nicht im Gegensatz stehe.

24 Vgl. Dahm, DR 1942, 401, 404; Freisler, DJ 1941, 929, 935.

25 Dahm, DR 1942, 401, 404; vgl. auch ders., Der Tätertyp im Strafrecht (Anm. 22), S. 187, 209f.; Mezger, Deutsches Strafrecht 1936, S. 30.

26 Siehe Müssig (Anm. 14), S. 83f.; umfassend dazu Kelker, Zur Legitimation von Gesinnungsmerkmalen im Strafrecht, 2007, S. 27 ff.

27 Schaffstein, in: Dahm et al. (Hrsg.) (Anm. 22), S. 108, 114.

28 Dahm, Verbrechen und Tatbestand, 1935, S. 62, 88; vgl. auch Freisler, in: Gürtner (Hrsg.) (Anm. 15), S. 11, $19 \mathrm{f}$.

29 Freisler, in: Gürtner (Hrsg.) (Anm. 15), S. 11, 18; Mezger (Anm. 25), S. 26, 29.

30 Freisler, in: Gürtner (Hrsg.) (Anm. 15), S. 11, 14, 23f.; ders., in: Gürtner/Freisler (Hrsg.), Das neue Strafrecht, 1936, S. 33, 134. 
Volksgemeinschaft ${ }^{31}$. Der Täter sollte also (auch) für die in der Tat zum Ausdruck gekommene sittliche Minderwertigkeit seiner Persönlichkeit bestraft werden, weil und insofern diese ihn als Feind der nationalsozialistischen Volksgemeinschaft auswies. Es war mithin die seine Persönlichkeit prägende Einstellung des Täters, die den Status der Mitgliedschaft oder des partiellen oder gänzlichen Ausgeschlossen-Seins aus der nationalsozialistischen Volksgemeinschaft vermittelte bzw. begründete.

\section{(3) Die methodische Dimension der Tätertypenlehre}

In methodischer Hinsicht bestand die Tätertypenlehre in der Einführung einer neuen beweglichen Gesetzgebungstechnik ${ }^{32}$. Die Orientierung an dem in der Volksanschauung lebendigen Täterbild sollte es dem Rechtsanwender ermöglichen, die Erfüllung des Mordtatbestandes abzulehnen, selbst wenn eines der Mordmerkmale des neu gefassten Tatbestandes verwirklicht worden war, wie auch umgekehrt, die Erfüllung des Mordtatbestandes zu bejahen, wenn der Täter keines der Mordmerkmale erfüllt hatte ${ }^{33}$. Die in $\S 211$ Abs. 2 RStGB aufgeführten Mordmerkmale besaßen nicht den Status einer Legaldefinition. Sie sollten lediglich eine Veranschaulichungsfunktion ausüben ${ }^{34}$ und dementsprechend wie Regelbeispiele gehandhabt werden ${ }^{35}$.

\section{c) Fazit und Konsequenzen}

Entgegen einer vor allem früher häufiger vertretenen Auffassung ${ }^{36}$ beruht das Gesetz zur Änderung des Reichsstrafgesetzbuchs vom 4. September 1941 durchaus auf der Tätertypenlehre einschließlich der nationalsozialistischen Ideologie ${ }^{37}$.

31 Vgl. Freisler, in: Gürtner (Hrsg.) (Anm. 15), S. 11, 13 f.; ders., in: Gürtner/Freisler (Hrsg.) (Anm. 30), S. 33, 133 ff.; Schmidt/Leichner, DR 1941, 2145; zu diesem elementaren Zusammenhang auch Marxen, Der Kampf gegen das liberale Strafrecht, 1975, S. 189.

32 So ausdrücklich Dahm, DR 1942, 401, 403.

33 Rüping, JZ 1979, 617, 618; Linka (Anm. 10), S. 186; Grünewald, Das vorsätzliche Tötungsdelikt, 2010, S. 43.

34 Freisler, DJ 1941, 929, 935; Dahm, DR 1942, 401, 404.

35 Frommel, JZ 1980, 559, 562f.; Geilen, JR 1980, 309, 311; Wehrle, Justiz-Strafrecht und polizeiliche Verbrechensbekämpfung im dritten Reich, 1989, S. 341f., 345; Grünewald (Anm. 33), S. 43.

36 Siehe dazu Thomas (Anm. 12), S. 246.

37 Es ist daher fragwürdig, wenn Kubiciel, Festschrift für v. Heintschel-Heinegg, 2015, S. 267, 270, aufgrund der bis auf $S t o o ß$ zurückgehenden Historie der Verwerflichkeitskonzeption behauptet, es sei vergröbernd, den § 211 StGB als Erblast der NS-Diktatur zu bezeichnen. 
Es kann gleichwohl dahinstehen, ob und inwieweit die Rechtsprechung des Reichsgerichts die Tätertypenlehre bei $\S 211$ StGB anerkannt und umgesetzt hat ${ }^{38}$. Denn dass die Einbettung der täterstrafrechtlichen Ausgestaltung des Mordtatbestandes in das nationalsozialistische Rechtsdenken in unserem heutigen Rechtsstaat gegenstandslos geworden ist, bedarf keiner näheren Begründung. So wurde nach dem Zweiten Weltkrieg die Tätertypenlehre einhellig abgelehnt ${ }^{39}$. Es ist insoweit zu begrüßen, dass die Expertengruppe einstimmig empfohlen hat, den auf den Tätertypus zielenden Wortlaut („Mörder“ bzw. „Totschläger“) durch eine an die Tathandlung anknüpfende Fassung $\mathrm{zu}$ ersetzen ${ }^{40}$. Eine inhaltliche Änderung des Tatbestandes ist mit diesem Vorschlag allerdings nicht verbunden. Es bleibt damit das Problem bestehen, wie man die durchgängig gesinnungsstrafrechtlich konzipierten Mordmerkmale ${ }^{41}$ der noch heute geltenden Fassung des $\S 211$ StGB erklären bzw. legitimieren kann ${ }^{42}$.

\section{Das Problem der Legitimation der Mordmerkmale}

\section{a) Das Leitprinzip der Verwerflichkeit}

Ungeachtet des aufgezeigten historischen Hintergrundes wird bis heute an dem Verwerflichkeitskonzept festgehalten. Als Bezugspunkt der Verwerflichkeit wird jedoch nunmehr die Tat und nicht der Täter herangezogen ${ }^{43}$. Auch die Expertengruppe hat die Verwerflichkeit der Tat mit relativer Mehrheit als taugliches Leitprinzip (neben anderen Leitprinzipien) anerkannt ${ }^{44}$. Man differenziert dabei häu-

38 Ablehnend RGSt. 76, 297; vgl. aber RGSt. 77, 41, 43; anders der Standpunkt des Reichsgerichts im Bereich des Kriegsstrafrechts, RGSt. 76, 313, 314f.; 88, 90; 91, 93.

39 Stock, SJZ 1947, Sp. 529, 550 f.; Jagusch, SJZ 1949, Sp. 324, 325; Schröder, SJZ 1950, Sp. 560, 565; Rieß, NJW 1968, 628, 629.

40 Beratungsergebnisse, in: Abschlussbericht (Anm. 4), S. 27; begrüßend Saliger, ZIS 2015, 600, 601: rechtshistorisch überfällig; Beck, ZIS 2016, $10,14$.

41 Zur Heimtücke siehe ausführlich Beck, ZIS 2016, 10, 13.

42 Vgl. auch die Einschätzung von Heine, GA 2000, 301, 307: „Vakuum“.

43 Jähnke, in: Leipziger Kommentar, StGB, Band 5, 11. Aufl. 2011, § 211 Rdn. 1; Eser/SternbergLieben, in: Schönke/Schröder, 29. Aufl. 2014, § 211 Rdn. 5; Lackner/Kühl, StGB, 28. Aufl. 2014, Vor $\S 211$ Rdn. 18; Momsen, in: Satzger/Schluckebier/Widmaier, 2. Aufl. 2014, § 211 Rdn. 3; Wessels/ Hettinger, Strafrecht Besonderer Teil, Band 1, 39. Aufl. 2015, Rdn. 73; Merkel, ZIS 2015, 429, 434; partiell auf die besondere Verwerflichkeit zurückgreifend Neumann, in: Nomos Kommentar zum StGB, Band 2, 4. Aufl. 2014, Vor § 211 Rdn. 152; Eschelbach, in: v. Heintschel-Heinegg, StGB, 2. Aufl. 2015, § 211 Rdn. 1; einschränkend Safferling, in: Matt/Renzikowski, 2013, § 211 Rdn. 3, der meint, dass dies nicht der eigentliche Grund der Strafschärfung sei.

44 Beratungsergebnisse, in: Abschlussbericht (Anm. 4), S. 30. 
fig zwischen der besonderen Verwerflichkeit des Beweggrundes, der Art der Tatausführung und des Tatzwecks ${ }^{45}$. Der Wechsel des Bezugspunkts der Verwerflichkeit stellt freilich den Mordtatbestand nicht schon für sich auf ein tragfähiges Fundament. Dieser Vorbehalt wird unabweisbar, wenn man zumindest die Einordnung der Mordmerkmale der ersten und dritten Gruppe als besondere persönliche Merkmale im Sinne des $§ 28$ StGB berücksichtigt. Diese sind gerade dadurch definiert, dass sie schwerpunktmäßig den Täter und nicht die Tat charakterisieren $^{46}$. Es liegt daher der Verdacht nahe, dass die rein nominelle Änderung der Kennzeichnung des Bezugsgegenstandes lediglich rhetorischer Natur ist und kaum substantielle Aussagekraft hat.

Als prädestiniertes Exerzierfeld für die Veranschaulichung der Legitimationsschwierigkeiten sei das Mordmerkmal der niedrigen Beweggründe herausgegriffen. Es bildet nicht nur den Oberbegriff für die Mordmerkmale der ersten, sondern nach Auffassung der Rechtsprechung auch für die Mordmerkmale der dritten Gruppe ${ }^{47}$. Die Expertengruppe hat für die Beibehaltung der Motivgeneralklausel plädiert. Das Mordmerkmal der Mordlust soll in seinem Kernbereich zwar beibehalten, inhaltlich aber geändert werden. Beim Mordmerkmal der Befriedigung des Geschlechtstriebs wurde lediglich eine sprachliche Änderung angeregt. Das Mordmerkmal der Habgier soll unverändert übernommen werden ${ }^{48}$. Darüber hinaus hat die Expertengruppe vorgeschlagen, die Mordmerkmale der ersten Gruppe durch die Merkmale „wegen des Geschlechts“, „wegen der ethnischen oder sonstigen Herkunft“, „wegen des Glaubens oder der religiösen Anschauung“, „,aus rassistischen Beweggründen“ und „wegen der sexuellen Identität“ zu ergänzen. Abgelehnt wurde hingegen die Implementierung der Merkmale „wegen der Abstammung“, „,wegen der politischen Anschauung“, wegen der „Inkonnexität zwischen Tatanlass und Tatfolgen“ und ,in selbstjustizieller Bestrafungsabsicht“. Die Entscheidung über die Merkmale „wegen der Weltanschauung“ und „aus grober Selbstsucht“ fiel unentschieden aus ${ }^{49}$. Die Mordmerkmale der dritten Gruppe hat die Kommission nicht angetastet ${ }^{50}$.

45 Eser/Sternberg-Lieben, in: Schönke/Schröder (Anm. 43), § 211 Rdn. 5; Rengier, Strafrecht Besonderer Teil, Band II, 15. Aufl. 2014, § 4 Rdn. 6; Wessels/Hettinger, Strafrecht Bes. Teil 1 (Anm. 43), § 2 Rdn. 73; vgl. noch Rieß, NJW 1968, 628, 629, der die Verwerflichkeit nur auf die Gesinnung bezogen, nicht aber als ausschließlichen Erklärungsansatz herangezogen hat.

46 BGHSt. 22, 375, 378; 23, 39, 40; 39, 326, 328.

47 Vgl. BGHSt. 23, 39, 40; 50, 6, 9; kritisch Neumann, in: NK StGB (Anm. 43), § 211 Rdn. 97, bezüglich der Verdeckungsabsicht.

48 Beratungsergebnisse, in: Abschlussbericht (Anm. 4), S. $32 \mathrm{ff}$.

49 Beratungsergebnisse, in: Abschlussbericht (Anm. 4), S. $32 \mathrm{ff}$.

50 Beratungsergebnisse, in: Abschlussbericht (Anm. 4), S. $48 \mathrm{ff}$. 
Kann die Verwerflichkeit die Steigerung der Strafwürdigkeit bei Tötungen aus niedrigen Beweggründen erklären? Niedrig sind Beweggründe nach ständiger Rechtsprechung dann, wenn die Tatantriebe nach allgemeiner sittlicher Wertung auf tiefster Stufe stehen, durch hemmungslose Eigensucht bestimmt und deshalb besonders verachtenswert sind ${ }^{51}$. Die Beurteilung soll aufgrund einer Gesamtwürdigung erfolgen, welche die Umstände der Tat, die Lebensverhältnisse des Täters und seine Persönlichkeit einschließt sowie alle äußeren und inneren Faktoren, die für die Handlungsantriebe des Täters maßgeblich waren ${ }^{52}$. Das Motiv muss jeglichen nachvollziehbaren Grundes entbehren ${ }^{53}$. Lässt sich aufgrund einer derartigen Gesamtwürdigung ein unerträgliches Missverhältnis von Tatanlass und Tat erweisen, soll das Motiv besonders verwerflich sein ${ }^{54}$. In ganz ähnlicher Manier wird auf die Unangemessenheit der Zweck-Mittel-Relation abgestellt ${ }^{55}$. Auch die Expertengruppe hat sich in der Begründung ihrer Auswahl der Leitprinzipien auf die Zweck-Mittel-Relation zwischen Tatanlass und Tatfolgen gestützt ${ }^{56}$. Neumann zufolge soll die besondere Verwerflichkeit aus der Instrumentalisierung des Opfers zu egoistischen Zwecken resultieren ${ }^{57}$. Nicht anderes scheint gemeint $\mathrm{zu}$ sein, wenn als weiteres Kriterium die solipsistische Rücksichtslosigkeit der Selbstverwirklichung angeführt wird ${ }^{58}$. Des Weiteren wird vorgeschlagen, dass Tötungsmotive, die den Anspruch des Opfers auf Achtung des personalen Eigenwerts schlechthin negieren, sittlich auf tiefster Stufe stehen ${ }^{59}$. Es findet sich zudem die interessante und aufschlussreiche Erwägung, dass das Opfer dem Täter keinen äußeren Anlass zur Tötung gegeben habe ${ }^{60}$.

Nach Auffassung von Kelker, die Überlegungen von Köhler aufgreift ${ }^{61}$, soll höchste Verwerflichkeit dann vorliegen, wenn der Täter das wechselseitige Anerkennungsverhältnis grundlegend verletzt, indem er entweder dem anderen ganz grundsätzlich jeglichen Achtungsanspruch abspricht oder weil er den ande-

51 BGHSt. 2, 60, 62; 3, 132, 133; 35, 116, 127; 42, 226; 47, 128; 50, 1, 8.

52 BGHSt. 35, 116, 127.

53 BGH StV 1998, 130; NJW 2005, 996, 998.

54 BGH NStZ 2006, 284, 285f.; Momsen, in: Satzger/Schluckebier/Widmaier (Anm. 43), § 211 Rdn. 34; Sinn, in: Systematischer Kommentar zum StGB, Stand: 148. Lfg. (Dezember 2014), § 211 Rdn. 12, 20; Otto, Jura 1994, 141, 145; Mitsch, JuS 1996, 121, 125.

55 Hilgendorf, in: Arzt/Weber/Heinrich/Hilgendorf, Strafrecht Besonderer Teil, 2. Aufl. 2009, § 2 Rdn. 72.

56 Beratungsergebnisse, in: Abschlussbericht (Anm. 4), S. 35.

57 Neumann, in: NK StGB (Anm. 43), § 211 Rdn. 6.

58 Heine, Tötung aus „niedrigen Beweggründen“, 1988, S. 210 ff., $238 \mathrm{ff}$.

59 Jähnke, in: LK (Anm. 43), § 211 Rdn. $26 \mathrm{ff}$.

60 Vgl. BGH NJW 1994, 2629; NStZ 2002, 84 f.

61 Köhler, GA 1980, 121, 130 ff. 
ren nicht als Zweck achtet, sondern ihn in seiner körperlichen Existenz zur Verwirklichung ausschließlich egoistischer Eigeninteressen herabwürdigt ${ }^{62}$. Den ersten Fall einer grundsätzlichen Missachtung des Achtungsanspruchs nimmt sie dann an, wenn dem Opfer aufgrund bestimmter Merkmale - Geschlecht, Religion, Herkunft, Hautfarbe etc. - die Erfüllung des Anspruchs auf Achtung als freies Subjekt verweigert wird - wie zum Beispiel bei einer Tötung aus Rassenhass ${ }^{63}$.

Man hat gegen das Verwerflichkeitstheorem geltend gemacht, dass bei anderen Straftatbeständen die verwerfliche Gesinnung die Strafbarkeit nicht gleichermaßen beeinflusse ${ }^{64}$. In der Tat wird diese in $\S 46$ Abs. 2 StGB als bloßer Strafzumessungsfaktor aufgeführt. Der Hinweis auf diesen Wertungswiderspruch ist von aktueller Brisanz, weil der Gesetzgeber durch Artikel 2 des Gesetzes zur Umsetzung der Empfehlungen des NSU-Untersuchungsausschusses des Deutschen Bundestags, das am 1. August 2015 in Kraft getreten ist ${ }^{65}$, in $\S 46$ Abs. 2 StGB den Passus aufgenommen hat, dass vom Gericht bei der Abwägung der für und gegen den Täter sprechenden Umstände besonders rassistische, fremdenfeindliche oder sonstige menschenverachtende Beweggründe und Ziele strafschärfend zu berücksichtigen seien. Das Gesetz geht auf einen Gesetzentwurf des Bundesrats vom 18. April 2012 zurück, in dem dieser sich zur Begründung vor allem auf einen erhöhten Unrechtsgehalt sog. Hassdelikte und eine größere Störung des sozialen Friedens berufen hat ${ }^{66}$. Die Bundesregierung hatte seinerzeit in ihrer Stellungnahme noch eher zurückhaltend reagiert, weil das geltende Recht in $\S 211$ StGB und $\S 46$ Abs. 2 StGB schon die Berücksichtigung derartiger Motive ermögliche, die Gesetzesänderung daher mehr symbolischer Natur sei ${ }^{67}$. Der Gesetzgeber hat durch die Übernahme des Vorschlags an Faktoren angeknüpft, deren Implementierung die Expertengruppe ebenfalls bejaht, aber auch an Faktoren, deren Implementierung die Expertengruppe gerade abgelehnt hat. An der unterschiedlichen Gewichtung der Gesinnungen je nach Deliktstyp ändert diese Divergenz freilich nichts. Was das Mordmerkmal der niedrigen Beweggründe anbetrifft, so wird ganz generell gerügt, dass die Gesamtwürdigung die Strafzumessung vorwegnehme ${ }^{68}$. Durch das Erfordernis einer Gesamtwürdigung falle das Mordmerkmal der niedrigen Beweggründe mit der allgemeinen Verwerflich-

62 Kelker (Anm. 26), S. $611 \mathrm{ff}$.

63 Kelker (Anm. 26), S. 487.

64 Hilgendorf, in: Arzt/Weber/Heinrich/Hilgendorf, Strafrecht Bes. Teil (Anm. 55), § 2 Rdn. 20.

65 BGBl. 2015 I S. 925.

66 BT-Drucks. 17/9345 S. 1; ebenso schon der Gesetzentwurf der SPD-Fraktion vom 14. Dezember 2011; BT-Drucks. 17/8131 S. 1.

67 BT-Drucks. 17/9345 S. 7.

68 Grünewald (Anm. 33), S. 101. 
keitsklausel zusammen ${ }^{69}$. Es bestehe eine Kluft zu anderen Mordmerkmalen, bei denen auf eine Gesamtwürdigung verzichtet werde ${ }^{70}$. Fundamentaler ist die Kritik, dass es in unserer pluralistischen Gesellschaft an einer allgemeinverbindlichen Feststellung von sozialethischen Wertungen fehle ${ }^{71}$. Die Folge ist - so die zutreffende Diagnose von Kargl - eine unkontrollierbare Richtermoral und damit ein Konflikt mit dem Bestimmtheits-, dem Gleichheits- und dem Verhältnismäßigkeitsgrundsatz ${ }^{72}$.

Die grundsätzlichere und somit entscheidende Frage lautet jedoch, ob die Verwerflichkeit des Beweggrundes überhaupt die Höhe des verwirklichten Unrechts und der Schuld beeinflussen kann. Mitglieder der Expertengruppe haben die Auffassung vertreten, dass die niedrigen Beweggründe das Handlungsunrecht der Tat steigern ${ }^{73}$. Von einer Steigerung des Unrechts selbst bei den täterbezogenen Mordmerkmalen gehen Rechtsprechung und wohl herrschende Meinung in der Literatur aus ${ }^{74}$. Ist diese Ansicht tragfähig? In einer freiheitlichen Rechtsordnung besteht das strafrechtliche Unrecht in dem Eingriff in äußere Rechtssphären bzw. Rechtspositionen anderer durch Übertretung der sie schützenden strafrechtlich bewehrten Verhaltensnormen ${ }^{75}$. In Übereinstimmung damit begeht der Täter eines Tötungsdelikts deswegen Unrecht, weil er das strafrechtliche Tötungsverbot übertritt und damit in das Lebensrecht des Opfers eingreift. Insoweit übernimmt das Handlungsunrecht jedoch lediglich die ausschließliche Funktion, dem Täter das objektive Tatunrecht auf einer ersten Stufe personal zuzurechnen. Diese $\mathrm{Zu}$ rechnungsfunktion wird aber nur durch den Vorsatz und nicht durch die Beweggründe des Täters erfüllt. Niedrige Beweggründe stellen zwar eine in der Tat zum Ausdruck kommende verwerfliche Gesinnung des Täters unter Beweis. Diese

69 Geilen, Festschrift für Bockelmann, 1979, S. 613, 642.

70 Grünewald (Anm. 33), S. 101.

71 Geilen, Festschrift für Bockelmann, S. 613, 619; Woesner, NJW 1980, 1136, 1137; ders., NJW 1980, 1136, 1137; Schroeder, JuS 1984, 275, 276; Kargl, StraFo 2001, 365, 367; Müssig (Anm. 14), S. 106; Grünewald (Anm. 33), S. 46, 119f., 131.

72 Kargl, StraFo 2001, 365, 367.

73 So Merkel, in: Abschlussbericht (Anm. 4), S. 658, 669; Schneider, in: Abschlussbericht (Anm. 4), S. 830, 839.

74 BGHSt. 1, 368, 371f.; Jähnke, in: LK (Anm. 43), Vor § 211 Rdn. 47; Sinn: in: SK StGB (Anm. 54), $\S 211$ Rdn. 4; Schneider, in: Münchener Kommentar, StGB, Band 3, 2. Aufl. 2012, Vor § 211 Rdn. 138, 145 ff.; Krey/Hellmann/Heinrich, Strafrecht Besonderer Teil, Band 1, 15. Aufl. 2012, § 1 Rdn. 23; Rengier, Strafrecht Bes. Teil II (Anm. 45), § 4 Rdn. 7; Otto, Jura 1994, 141, 145; Paeffgen, GA 1982, 255, 271; Rüping, JZ 1979, 617, 619f.; Safferling, in: Matt/Renzikowski (Anm. 43), § 211 Rdn. 3: Gössel/Dölling, Strafrecht Besonderer Teil, Band 1, 2. Aufl. 2004, § 1 Rdn. 21.

75 Haas, Kausalität und Rechtsverletzung, 2002, S. 54 ff.; ders., Die Theorie der Tatherrschaft und ihre Grundlagen, 2008, S. $58 \mathrm{ff} . ;$ Renzikowski, GA 2007, $561 \mathrm{ff}$. 
kann aber als solche das Unrecht der Tat schon deswegen nicht erhöhen, weil die Rechtsgemeinschaft keinen rechtlichen Anspruch gegenüber dem Täter hat, eine bestimmte missbilligenswerte Einstellung nicht zu haben oder zum Ausdruck zu bringen $^{76}$. Was das Haben der Gesinnung anbetrifft, folgt dies schon daraus, dass Gesinnungen nicht mit Rechtszwang durchsetzbar sind. Ist aber das Haben der Gesinnung nicht rechtswidrig, gibt es in der Regel keinen Grund, das Äußern dieser Gesinnung als Rechtsverletzung zu qualifizieren. Des Weiteren ist zu beachten, dass der Staat ein Zusammenschluss seiner Bürger zum Schutze ihrer Rechte und zur Gewährleistung von Daseinsvorsorge ist. Die Rechte der Bürger und die Gewährleistung von Daseinsvorsorge werden aber weder durch das bloße Haben noch durch das bloße Äußern einer verwerflichen Gesinnung tangiert ${ }^{77}$. Der Staat ist keine prävalente Instanz, die einen Zugriff auf die Totalität der Person hat. Die Einstellung betrifft daher grundsätzlich nur die Sphäre der Moralität. Mit dieser Einsicht wäre es nicht zu vereinbaren, schon das Zum-AusdruckBringen einer derartigen Einstellung als Rechtsfriedensdelikt zu sanktionieren ${ }^{78}$. Der Rechtsfrieden ist kein eigenes autarkes Rechtsgut, sondern seine Störung nur eine Nebenbedingung strafrechtlicher Intervention ${ }^{79}$. Eine nur scheinbare Ausnahme gilt für die genau genommen polizeirechtlich ansetzende Spezialprävention. Insoweit ist die Einstellung des Täters lediglich ein Umstand, der seine Gefährlichkeit begründet ${ }^{80}$.

Grünewald ist Recht zu geben, dass nur schwer verständlich wäre, warum der Gegenstand des Unrechts etwas sein soll, das über eine vorsätzliche Rechtsgutsverletzung hinausreicht, wenn das Recht nur die äußere Freiheit zu seinem Gegenstand hat. Das Unrecht ist nur die Verkehrung des Rechts ${ }^{81}$. Entgegen der Ansicht von Merkel beruht der Vorwurf der Vermischung von Legalität und Moralität nicht auf einem Missverständnis. Sein Argument, dass als Gegenstand der strafrechtlichen Beurteilung nur Handlungen und nicht bloße Köperbewegungen in Betracht zu ziehen seien ${ }^{82}$, belegt keineswegs die Unrechtsrelevanz von Beweggründen bzw. Gesinnungen. Bloße Körperbewegungen sind nicht normierbar. Die strafrechtlich bewehrten Verhaltensnormen appellieren (unter anderem) an den menschlichen Willen: ohne Willkürlichkeit und Vorsatz bzw. Fahrlässig-

76 Siehe Haas, Strafbegriff, Staatsverständnis und Prozessstruktur, 2008, S. 249 Fn. 62.

77 Anderes gilt möglicherweise dann, wenn das Verhalten über das bloße Äußern der Gesinnung hinausreicht, indem der Täter andere beispielsweise zur Begehung von Straftaten aufstachelt.

78 Vgl. aber BT-Drucks. 17/8131 S. 1; 17/9345 S. 1.

79 Haas, ZStW 123 (2011), S. 226, 230.

80 Dazu siehe Timm, Gesinnung und Straftat, 2012, S. $38 \mathrm{ff} ., 111 \mathrm{ff} ., 124 \mathrm{ff}$.

81 Grünewald (Anm. 33), S. $114 \mathrm{ff}$.

82 Merkel, in: Abschlussbericht (Anm. 4), S. 658, 667 ff.; ders., ZIS 2015, 429, $434 \mathrm{ff}$. 
keit kein Verhaltensnormversto ${ }^{83}$. Warum die Rechtsordnung „katastrophal schlecht beraten“ wäre, das Gewicht des Unrechts nicht von subjektiven (mentalen) Unterschieden abhängig zu machen ${ }^{84}$, zeigt Merkel nicht.

Man könnte gleichwohl überlegen, ob die Missachtung des Achtungsanspruchs, auf die sich Kelker bezieht, ein valider Anknüpfungspunkt ist, der nicht erst die Schuld, sondern womöglich schon das Unrecht tangiert. Kelker selbst hat dies jedoch in Abrede gestellt: Die fundamentale Verletzung des wechselseitigen Anerkennungsverhältnisses soll nicht das in der vorsätzlich herbeigeführten Freiheitsverletzung und der darauf beruhenden Negation der Normgeltung bestehende Unrecht der Tat steigern. Die Tötung eines anderen soll schon für sich höchstes Unrecht verwirklichen ${ }^{85}$. Gleichwie: Man könnte überlegen, ob nicht jedes vorsätzliche Delikt, sofern es höchstpersönliche Rechtsgüter zu seinem Gegenstand hat, nicht nur eine Verletzung der vom Tatbestand geschützten Rechtsposition, sondern zugleich eine Beleidigung der Person des Rechtsgutsträgers (im weiteren Sinne) ist - eine übrigens noch im 19. Jahrhundert übliche Sichtweise ${ }^{86}$. Anknüpfen könnte man daher an den Standpunkt von Kelker, dass eine Tötung aus verwerflicher Gesinnung in besonderem Maße das Opfer herabwürdigt ${ }^{87}$. Auch von anderer Seite wird die Auffassung vertreten, dass die besondere Verwerflichkeit der Tat aus dem Verstoß gegen die Menschenwürde infolge der Instrumentalisierung des Opfers resultiert ${ }^{88}$. Ebenso wird in der Begründung des Abschlussberichts für die Auswahl der Leitprinzipien und für die Beibehaltung der Motivgeneralklausel auf die von Mitgliedern der Expertengruppe vertretene Auffassung verwiesen, dass der Täter unter Umständen die Menschenwürde des Opfers negiere ${ }^{89}$. Es ist freilich zu berücksichtigen, dass die Expertengruppe ohne weitere Begründung die Möglichkeit geleugnet hat, den Grundfall der Tötung von der höchststrafwürdigen Tötung anhand des Kriteriums des Verstoßes gegen die Menschenwürde bzw. das Diskriminierungsverbot unterscheiden $z u$ können ${ }^{90}$.

83 Dazu Haas, Kausalität und Rechtsverletzung (Anm. 75), S. 74 f.; Renzikowski, in: Alexy (Hrsg.), Juristische Grundlagenforschung, ARSP-Beiheft 104 (2005), S. $115 \mathrm{ff}$.

84 Merkel, ZIS 2015, 429, 435.

85 Kelker (Anm. 26), S. 479 ff., 590 ff., 614.

86 Bauer, Lehrbuch des Strafrechts, 2. Aufl. 1833, § 204, S. 299f.: Abegg, Lehrbuch der Strafrechtswissenschaft, 1836, § 217, S. 307 und § 287, S. 392f.; Feuerbach, Lehrbuch des peinlichen Rechts, 14. Aufl. 1847, § 21, S. 45; Marezoll, Das gemeine deutsche Criminalrecht, 1856, § 424, S. $432 \mathrm{ff}$.

$87 \operatorname{Kelker}($ Anm. 26), S. $479 \mathrm{ff} ., 611 \mathrm{ff}$.

88 Neumann, in: NK StGB (Anm. 43), Vor § 211 Rdn. 152.

89 Beratungsergebnisse, Abschlussbericht (Anm. 4), S. 29, 35.

90 Beratungsergebnisse, Abschlussbericht (Anm. 4), S. 30. 
In der Tat: $\mathrm{Zu}$ beachten ist, dass die Verdinglichung des Opfers, die die Menschenwürdeverletzung begründen soll, grundsätzlich Kennzeichen einer jeden Tötung ist - sei es dass das Opfer zum Objekt heterogener Zweckdurchsetzung degradiert wird, sei es dass der Anspruch des Opfers, als moralisch Gleicher anerkannt zu werden, diesem vornherein abgesprochen wird - wie zum Beispiel bei Tötungen aus rassistischen Gründen ${ }^{91}$. Es kann daher nicht der Ansicht von Hörnle beigepflichtet werden, dass in Fällen von „hate crime“ das Opfer besonders gedemütigt und herabgewürdigt werde ${ }^{92}$. Dasselbe gilt für das geltend gemachte krasse Missverhältnis von Tat und Tatanlass. Insoweit ist zu Recht der Einwand erhoben worden, dass keine Abwägung zwischen der Tötung und dem Tatzweck stattfinde. Die Tötung des Opfers ist immer unverhältnismäßig ${ }^{93}$. Zutreffend hat schon Geilen diagnostiziert, dass dieses Missverhältnis grundsätzlich immer bestehe und dass daher der Mordtatbestand zum Regelfall werde ${ }^{94}-$ mit der Konsequenz, dass der Mordtatbestand zum Grundtatbestand der Tötungsdelikte mutiert ${ }^{95}$. Fragt man sich, unter welchen Voraussetzungen das Opfer nicht im gleichen Maße verdinglicht wird, kommen - beschränken wir uns zunächst auf die Rechtswidrigkeitsebene - nur Fälle in Betracht, in denen das Tatmotiv bzw. der Tatzweck dem Opfer unrechtsmindernd entgegengehalten werden kann. Als Beispiel wäre die Teilverwirklichung eines Rechtfertigungsgrundes zu nennen. Insoweit kommt also den subjektiven Mordmerkmalen lediglich die Funktion $\mathrm{zu}$, klarzustellen, dass keine Umstände vorliegen, die das Tötungsunrecht mildern $^{96}$.

Alternativ wäre $\mathrm{zu}$ erwägen, ob nicht das Mordmerkmal der niedrigen Beweggründe die Schuld erhöht. Dies entspricht der Ansicht von Kelker ${ }^{97}$. Auch Teile der Literatur ordnen zumindest die Mordmerkmale der ersten und dritten

91 Haas, Festschrift für Weber, 2004, S. 235, 248; ders., Strafbegriff, Staatsverständnis und Prozessstruktur (Anm. 76), S. 282; ebenso Grünewald (Anm. 33), S. 164 ff.; dies., in: Abschlussbericht (Anm. 4), S. 477, $497 \mathrm{ff}$.

92 Hörnle, Tatproportionale Strafzumessung, 1999, S. 272f.; dies., JZ 1999, 1080, 1089.

93 Neumann, in: NK StGB (Anm. 43), § 211 Rdn. 152, ohne daraus allerdings systematische Strafwürdigkeitsüberlegungen abzuleiten.

94 Geilen, Festschrift für Bockelmann, S. 613, 642; Rüping, JZ 1979, 617, 620; Müssig (Anm. 14), S. 116.

95 Gössel, DRiZ 1980, 281, 286.

96 Vgl. schon Grünewald (Anm. 33), S. 163; insoweit ist die Ansicht von Hilgendorf, in: Arzt/ Weber/Heinrich/Hilgendorf, Strafrecht Bes. Teil (Anm. 55), § 2 Rdn. 20, die Begründung besonderer Verwerflichkeit stehe vor dem Problem, dass bei Mord und Totschlag gleiches Unrecht verwirklicht werde, zutreffend.

97 Kelker (Anm. 26), S. 479 ff., 590 ff., 614. 
Gruppe als spezielle Schuldmerkmale ein ${ }^{98}$. Die genaue Antwort, wie das durch die Unrechtsmaxime bestimmte „Ausmaß der Geltungsverkehrung“ des wechselseitigen Anspruchs auf Achtung Einfluss auf die Höhe der Schuld nehmen kann, ist Kelker allerdings schuldig geblieben. Sie findet sich aber bei Köhler am Beispiel der Instrumentalisierung fremden Lebens: Die Rangordnung von Leben und partikulär-egoistischen Interessen sei so eindeutig und für den Vernünftigen so selbstverständlich, dass die freie Aufhebung dieser Geltungsansprüche im Verschuldensprozess besonderen Widerstand überwinden müsse, also besondere Verderbtheit des Täters indiziere ${ }^{99}$. Köhler beruft sich also in der Sache auf die Hemmschwellentheorie der Schuld: Je höher die Hemmschwelle, die der Täter überwinden muss, desto höher ist seine Schuld.

Aber auch dieser Erklärung stehen durchschlagende Bedenken entgegen. Die Schuld - genauer: die Strafbegründungsschuld - ist eine Zurechnungskategorie. Die materiellen Schuldelemente legen die Voraussetzungen fest, unter denen das Unrecht dem Täter vorgeworfen werden kann. Dann aber kann die Schuld nicht erhöht werden, weil mehr als volle Zurechnung nicht möglich ist. Die Schuld kann nur gemindert oder ausgeschlossen sein ${ }^{100}$. Die Validität dieser Einsicht wird auch nicht durch die Hemmschwellentheorie erschüttert. Aus den vorangehenden Ausführungen sollte deutlich geworden sein, dass der Täter jene Hemmungskraft der Unrechtseinsicht zu überwinden hat, die der Tatbestand in Anbetracht des geschützten Rechtsguts ohnehin voraussetzt. Auf der Schuldebene kann es daher nur um Fälle gehen, in das Tatmotiv bzw. der Tatzweck Folge oder Ausdruck einer schuldmindernden Disposition des Täters ist. Kann angesichts des mentalen Zustandes des Täters das Tatmotiv bzw. der Tatzweck dem Opfer schuldmindernd entgegengehalten werden, wäre dies aber lediglich ein weiterer Grund, der das Vorliegen niedriger Beweggründe ausschließen könnte. So verneint die Rechtsprechung in einigen Entscheidungen das Vorliegen niedriger Beweggründe dann, wenn der Täter in einer Konfliktsituation aus Verzweiflung gehandelt hat ${ }^{101}$.

Hält man den von der herrschenden Meinung für sich reklamierten Tatbezug strikt durch, kann daher die Bewertung eines Beweggrundes als niedrig also nur

98 Engisch, GA 1955, 161, 166; Schmidhäuser, Gesinnungsmerkmale im Strafrecht, 1958, S. 223 ff.; Köhler, GA 1980, 121, 123, 130, 134; Lackner, NStZ 1981, 348; Jescheck/Weigend, Lehrbuch des Strafrechts, Allgemeiner Teil, 5. Aufl. 1996, § 42 II 2f.

99 Köhler, GA 1980, 121, 139.

100 Walter, Gedächtnisschrift für Hilde Kaufmann, 1986, S. 493, 504; Frisch, ZStW 99 (1987), S. 751, 774; Hörnle, JZ 1999, 1080, 1084; Haas, Strafbegriff, Staatsverständnis und Prozessstruktur (Anm. 76), S. 249 Fn. 62, 293; Grünewald (Anm. 33), S. 210 f.; Timm (Anm. 80), S. 178 ff., 184. 101 Vgl. BGH StV 1981, 399, 400; NStZ 2002, 368; 2004, 14; NStZ-RR 2004, 234. 
dann verneint werden, wenn Tatmotiv oder Tatzweck entweder das Unrecht oder doch zumindest die Schuld mindern ${ }^{102}$. Aus dieser Erkenntnis folgt zunächst, dass die durch die Empfehlungen der Expertengruppe noch weiter ausufernde, unübersichtliche Kasuistik der niedrigen Beweggründe vermieden werden könnte. Darüber hinaus wäre aus dieser Einsicht zu schließen, dass insoweit in Wahrheit der Mord als Grundtatbestand und der Totschlag als Privilegierung zu qualifizieren wären ${ }^{103}$. Ein derartiges implizites Zugeständnis kann aber nicht ohne Folgen für die Systematik der Tötungsdelikte insgesamt bleiben.

Die Einbeziehung von Bewertungsfaktoren wie Egoismus, Solipsismus und Selbstsucht lässt allerdings besorgen, dass die niedrigen Beweggründe ungeachtet dessen dazu dienen, ein moralisches Urteil über die Person des Täters zu fällen und ihm den Status als moralisch Gleicher in bestimmtem Maße zu entziehen. Der erhöhte Strafwürdigkeitsgehalt des Mordes gegenüber dem Totschlag läge dann in einer gesteigerten Bosheit des Täters, auf der wiederum seine gesteigerte moralische Ächtung fußen würde. Eine derartige moralische Ächtung steht allerdings einem Rechtsstaat, der auf der Menschenwürde fußt, gerade nicht $\mathrm{zu}^{104}$. Denn auch dem Täter, der sich durch seine Tat in unerträglicher Weise vergangen hat, kann die Menschenwürde nicht abgesprochen werden ${ }^{105}$. Es ist daher der Kritik Kargls zu folgen, dass die niedrigen Beweggründe deutliche Bezüge zur Charakterisierung des Täters im Sinne der Lehre vom normativen Tätertyp aufweisen ${ }^{106}$, wenn auch mit der sozialethischen Stigmatisierung nicht mehr eine Feinderklärung im Namen der nationalsozialistischen Volksgemeinschaft verbunden ist. Es ist ein schwerwiegender Mangel des Abschlussberichts, dass er keine Auskunft darüber enthält, warum die besondere Verwerflichkeit des Beweggrundes oder des Tatzwecks das Tatunrecht oder die Tatschuld erhöhen soll.

Die hier geäußerte Kritik gilt auch für die anderen Mordmerkmale, sofern sie auf die innere Einstellung des Täters rekurrieren, wie dies ursprünglich der Konzeption des nationalsozialistischen Gesetzgebers entsprach und wie dies heute noch von der Rechtsprechung und von Teilen der Literatur beim Mordmerkmal der Grausamkeit angenommen wird, das ein Handeln aus einer ge-

102 So schon Haas, Strafbegriff, Staatsverständnis und Prozessstruktur (Anm. 76), S. 252 f. Fn. 78; ebenso Grünewald (Anm. 33), S. 163; Hörnle, Festschrift für Frisch, 2013, S. 653, 669 ff.

103 Grünewald (Anm. 33), S. 163; Hörnle, Festschrift für Frisch, S. 653, 669 ff.; Timm (Anm. 80), S. $187 \mathrm{ff}$.

104 Ausführlich dazu Haas, Strafbegriff, Staatsverständnis und Prozessstruktur (Anm. 76), S. $244 \mathrm{ff}$.

105 So auch BVerfGE 64, 261 ff.; Kett-Straub, Die lebenslange Freiheitsstrafe, 2011, S. 46.

106 Kargl, StraFo 2001, 365, 367. 
fühllosen und mitleidlosen bzw. unbarmherzigen Gesinnung voraussetzen soll ${ }^{107}$. Sofern die Verwerflichkeit bei den anderen Mordmerkmalen hingegen allein aus objektiven unrechtsbezogenen Umständen begründet werden kann, ist dieser Kritik der Boden entzogen. Allerdings bestünde insofern kein Anlass mehr, in diesen Segmenten die Strafwürdigkeit mit einer der Moralsprache entlehnten Kategorie $\mathrm{zu}$ erläutern ${ }^{108}$, die bei anderen Tatbeständen zur Erfassung des Strafwürdigkeitsgehalts nicht angewendet wird.

\section{b) Das Leitprinzip der Tatgefährlichkeit}

\section{aa) Die Anknüpfung an die besonders gefährliche Begehungsweise}

Nicht selten wird die Auffassung vertreten, dass sich zumindest ein Teil der Mordmerkmale mit einer erhöhten Gefährlichkeit der Tat erklären lässt ${ }^{109}$. Auch die Expertengruppe hat die Gefährlichkeit der Tat als taugliches Leitprinzip anerkannt ${ }^{110}$. Dieser Erklärungsansatz wird insbesondere bei den Mordmerkmalen der zweiten Gruppe bemüht. So soll die besondere Strafwürdigkeit des Heimtückemordes auf der besonderen Gefährlichkeit des Vorgehens seitens des Täters beruhen $^{111}$. Vor allem die Rechtsprechung argumentiert, dass durch das Ausschalten von Verteidigungsoptionen das Vorgehen des Täters für das Opfer besonders gefährlich sei ${ }^{112}$.

Die Effektuierung der Tat durch das Ausnutzen der Arg- und Wehrlosigkeit des Opfers ist allerdings für sich gesehen kein Strafschärfungsgrund, wenn das heimtückische Vorgehen lediglich dafür gesorgt hat, dass die Tat überhaupt gelingen konnte. Dieses Maß an Gefährlichkeit ist in der vollendeten Tat impliziert. Zu Recht weist Grünewald darauf hin, dass der Täter immer eine - relative - Schwäche des

107 BGHSt. 3, 180, 181, 264; 49, 189, 196; BGH NStZ 1982, 379 f.; StV 1997, 565 f.; NStZ 2007, 402 ff.; 2008, 29ff.; Eser/Sternberg-Lieben, in: Schönke/Schröder (Anm. 43), § 211 Rdn. 27; Fischer, StGB, 63. Aufl. 2016, § 211 Rdn. 58.

108 Anders wohl Merkel, ZIS 2015, 429, 434.

109 Lackner/Kühl (Anm. 43), Vor § 211 Rdn. 18; Neumann, in: NK StGB (Anm. 43), Vor § 211 Rdn. 152; Safferling, in: Matt/Renzikowski (Anm. 43), § 211 Rdn. 3; Eschelbach, in: v. HeintschelHeinegg (Anm. 43), § 211 Vor Rdn. 1; Jähnke, in: LK (Anm. 43), § 211 Rdn. 1; Rieß, NJW 1968, 628, 629; Rüping, JZ 1979, 617; Köhler, GA 1980, 121.

110 Beratungsergebnisse, in: Abschlussbericht (Anm. 4), S. 29.

111 Sinn, in: SK StGB (Anm. 54), § 211 Rdn. 40; Neumann, in: NK StGB (Anm. 43), § 211 Rdn. 46; Schneider, in: MK (Anm. 74), § 211 Rdn. 144; Jähnke, in: LK (Anm. 43), § 211 Rdn. 40; Lackner/Kühl (Anm. 43), § 211 Rdn. 6; Wessels/Hettinger, Strafrecht Bes. Teil 1 (Anm. 43), Rdn. 105; Krey/Hellmann/Heinrich, Strafrecht Bes. Teil 1 (Anm. 74), § 1 Rdn. 41.

112 BGHSt. (GS) 11, 139, 141f.; 20, 301, 302; 30, 105, 116; (GS) 39, 353, 368; 41, 72, $78 \mathrm{f}$. 
Opfers ausnutzen muss, um die Tat begehen zu können ${ }^{113}$. Zudem besteht hinsichtlich der Gefährlichkeit kein Unterschied zu Fällen, in denen die Wehrlosigkeit des Opfers nicht auf seiner Arglosigkeit beruht. Dieser Umstand kann auf verschiedene Ursachen zurückzuführen sein. Möglich ist, dass das Opfer schon konstitutionell nicht die Fähigkeit zum Argwohn besitzt - wie bei Kleinstkindern, Schwerstkranken, die kein Gefahrbewusstsein entwickeln können, Bewusstlosen, die dazu aktuell nicht in der Lage sind, und unter Umständen Schlafenden ${ }^{114}$. Das Problem, inwieweit die Exemtion derartiger Opfergruppen anzuerkennen ist - maßgeblich ist die Frage, ob die Heimtücke eine Täuschung über die Erwartung, nicht körperlich angegriffen zu werden, voraussetzt -, bedarf keiner weiteren Erörterung. Denn möglich ist des Weiteren, dass der Täter über ein derartig überlegenes Tatmittel verfügt, dass entweder die Wehrlosigkeit des Opfers nicht auf seiner Arglosigkeit beruht oder das Opfer trotz seines Argwohns dem Täter wehrlos ausgeliefert ist ${ }^{115}$. Dies kann auch nach erfolgter Gegenwehr der Fall $\operatorname{sein}^{116}$. Das Mordmerkmal der Heimtücke ist also nicht geeignet, eine Unrechtssteigerung im Vergleich zu den ausgeschlossenen Fällen zu belegen ${ }^{117}$.

Die Rechtsprechung sieht der Sache nach das Problem und wendet daher das Mordmerkmal der Heimtücke unter anderem auch dann an, wenn der Täter dem Opfer offen entgegentritt, so dass das Opfer im Zeitpunkt des Tatbeginns argwöhnisch ist, ihm aber keine Zeit mehr zu effektiver Gegenwehr verbleibt. Dabei soll es keinen Unterschied machen, ob der überraschende Angriff von vornherein mit Tötungsvorsatz geführt wird, oder ob der ursprüngliche Verletzungswille derart schnell in den Tötungsvorsatz übergeht, dass der Überraschungseffekt bis zu dem Zeitpunkt fortdauert, in dem der Täter zu dem auf die Tötung gerichteten Angriff übergeht, so dass die Situation völlig unverändert ist und das Opfer keine Zeit mehr hat, Gegenmaßnahmen zu ergreifen ${ }^{118}$. Ähnliches gilt, wenn der Täter dem Opfer eine Falle stellt ${ }^{119}$. In allen diesen Fällen wird der Zeitpunkt der Arglosigkeit vorverlagert. Das Mordmerkmal der Heimtücke ist dann aber kaum noch eingrenz-

113 Grünewald (Anm. 33), S. 125; ihr zustimmend Beck, ZIS 2016, 10, 15

114 Vgl. dazu Grünewald (Anm. 33), S. 127 ff.; dies., in: Abschlussbericht (Anm. 4), S. 477, 487; Beck, ZIS 2016, 10, 11.

115 Vgl. Hilgendorf, in: Arzt/Weber/Heinrich/Hilgendorf, Strafrecht Bes. Teil (Anm. 55), § 2 Rdn. 49; Grünewald (Anm. 33), S. 125, die jeweils auf die gleiche Gefährlichkeit des konstitutionell überlegenen Täters hinweisen; Beck, ZIS 2016, 10, 17.

116 Neumann, in: NK StGB (Anm. 43), § 211 Rdn. 48; Beck, ZIS 2016, 10, 15.

117 Kelker (Anm. 26), S. 619, die meint, dass die besondere Gefährlichkeit nicht mehr substantiell ins Gewicht falle.

118 BGH NStZ-RR 1997, 168; NJW 2003, 1060; NStZ-RR 2004, 14, 16; 2005, 309; NStZ 2006, 167, 169; 2006, 502, 503; NStZ-RR 2007, 14; NStZ 2009, 29 f.; 2012, 35; siehe dazu Küper, GA 2014, 611 ff. 119 BGHSt. 22, $70 \mathrm{ff}$. 
bar. Es müsste konsequenterweise stets auch dann angewendet werden, wenn sich das Opfer bei Kenntnis der Tötungsabsicht des Täters schon im Vorfeld der eigentlichen Tatausführung der Tat hätte entziehen können. Dann aber wäre fast jeder Fall einer Tötung ein Fall von Heimtücke. Mit der Konzeption des Mordes als Tatbestand, der im Vergleich zum Totschlag einen erhöhten Strafwürdigkeitsgehalt verkörpert, ist dies nicht zu vereinbaren. Es stellt sich zudem die Frage, ob die Strategie der Rechtsprechung noch mit dem Wortlaut vereinbar ist ${ }^{120}$.

Die Empfehlungen der Expertengruppe sind bezüglich des Mordmerkmals der Heimtücke alles andere als in sich stimmig ausgefallen. Mit absoluter Mehrheit wurde beschlossen, die heimtückische Tatbegehung als Tatbestandsmerkmal zwar grundsätzlich beizubehalten, diese aber $\mathrm{zu}$ ändern ${ }^{121}$. Zugleich hat die Expertengruppe jeweils mit relativer Mehrheit dafür votiert, die Heimtücke durch das Merkmal „mittels eines hinterhältigen Angriffs“ bzw. durch das Merkmal „durch Ausnutzung der Arg- und Wehrlosigkeit oder einer aus anderen Gründen bestehenden Schutzlosigkeit“ zu ersetzen oder durch das Merkmal „oder Ausnutzung einer aus anderen Gründen bestehenden Schutzlosigkeit“ zu ergänzen ${ }^{122}$. Mit Hilfe des Merkmals „mittels eines hinterhältigen Angriffs“ soll offensichtlich die Rückkehr zum Koinzidenzprinzip gewährleistet werden, das eine Arglosigkeit zum Zeitpunkt des Versuchsbeginns fordert. Die Anwendung dieser Tatbestandsvariante soll auf Fälle beschränkt werden, in denen ein „eklatanter Handlungsunwert“ vorliegt ${ }^{123}$. Das Problem jedoch ist, dass bei einer heimlichen, auf Verdeckung der Tötungsabsicht gerichteten Vorgehensweise die Gefährlichkeit der Tat für das Opfer nicht höher sein muss als in Fällen, in denen diese Voraussetzungen nicht erfüllt sind.

Die zudem angeratene Einbeziehung von Fällen der Ausnutzung einer aus anderen Gründen bestehenden Schutzlosigkeit vermeidet zwar die Exemtion bestimmter Opfergruppen. Aber die Formulierung führt wiederum zum Wertungswiderspruch einer unterschiedlichen Behandlung gleich gefährlicher Verhaltensweisen, wenn man die Schutzlosigkeit absolut definiert und an konstitutionelle Defizite des Opfers anknüpft. Erschießt der Täter ein Baby, wäre die Tatbestandsvariante erfüllt, nicht aber, wenn das Opfer ein erwachsener Mensch gewesen wäre, der sich zwar an sich wehren kann, aber bei Gebrauch der Schusswaffe trotz fehlender Hinterhältigkeit ohne jede Chance gewesen wäre. Auch die Tötung eines Neugeborenen durch die Mutter, die ihr Kind „in oder gleich nach der Geburt“ (vgl. § 217 StGB a.F.) tötet, wäre eo ipso schon Mord. In der Begründung

120 Zweifelnd Beck, ZIS 2016, 10, 16.

121 Beratungsergebnisse, in: Abschlussbericht (Anm. 4), S. 43.

122 Beratungsergebnisse, in: Abschlussbericht (Anm. 4), S. 44.

123 Beratungsergebnisse, in: Abschlussbericht (Anm. 4), S. 43. 
wird auf diese Konsequenz hingewiesen ${ }^{124}$. Würde man zur Vermeidung dieser Widersprüche alle Fälle des Ausnutzens körperlicher oder waffentechnischer Überlegenheit einbeziehen ${ }^{125}$, wäre aus den oben genannten Gründen eigentlich fast jede vorsätzliche Tötung als Mord einzuordnen.

Damit wird zum gravierenden Problem übergeleitet, dass das Mordmerkmal der Heimtücke jene privilegierenden Umstände, die die Niedrigkeit der Beweggründe ausschließen können, nicht berücksichtigen kann. Sie spielen für die Erfüllung des Heimtückebegriffs keine Rolle. Die Expertengruppe hat diesen Punkt ansatzweise erkannt und in den Haustyrannenfällen auf die Ähnlichkeit zur Notwehr und zum Defensivnotstand hingewiesen. Für die Beibehaltung wurde freilich geltend gemacht, dass dieses Mordmerkmal in der Bevölkerung am präsentesten sei ${ }^{126}$. Ob die vorgeschlagene, noch unten anzusprechende Einführung eines Privilegierungstatbestandes insoweit den gordischen Knoten durchschlagen könnte, wird zu klären sein.

\section{bb) Die Anknüpfung an die Gefährdung oder Verletzung weiterer Rechtsgüter}

Was das Mordmerkmal der Grausamkeit anbetrifft, wird die gesteigerte Gefährlichkeit der Tat auf die Verletzung weiterer Opferinteressen gestützt ${ }^{127}$. Die Strafschärfung rechtfertige sich schon aufgrund des erhöhten Leidens seitens des Opfers $^{128}$. Freilich wird eingewandt, dass die Unrechtssteigerung angesichts des Höchstunrechts der Tötung nicht mehr signifikant ins Gewicht falle ${ }^{129}$. Grundsätzlicher ist die berechtigte Kritik, dass genau genommen das Tötungsunrecht selbst nicht erhöht wird, sondern zum Tötungsunrecht weiteres Unrecht durch den Eingriff in die körperliche Integrität des Opfers hinzutritt. Die Unrechtssteigerung resultiert aus der Koinzidenz zweier Eingriffe in unterschiedliche Rechtsgüter. Freilich ist zu beachten, dass einige Qualifikationstatbestände die Gefährdung oder Verletzung weiterer Rechtsgüter unter erhöhte Strafe stellen (vgl. nur die $\S \S 244,244 a, 250,251$ StGB). Gleichwohl wird aus gutem Grund gefragt, warum diese Fälle nicht auf der Ebene der Konkurrenzen verortet werden ${ }^{130}$. Würde man

124 Beratungsergebnisse, in: Abschlussbericht (Anm. 4), S. 43.

125 So der Vorschlag von Mitsch, JR 2015, 122, 123, 126.

126 Beratungsergebnisse, in: Abschlussbericht (Anm. 4), S. 42.

127 Neumann, in: NK StGB (Anm. 43), § 211 Rdn. 76.

128 Witt, Das Mordmerkmal „grausam“, 1996, S. 117; ebenso Schneider, in: MK (Anm. 74), § 211 Rdn. 130.

$129 \operatorname{Kelker}$ (Anm. 26), S. 625.

130 Grünewald (Anm. 33), S. 49, $168 \mathrm{ff}$; dies., in: Abschlussbericht (Anm. 4), S. 477, 483; vgl. auch Schroeder, JuS 1984, 271, 277; Arzt, ZStW 83 (1973), S. 1, 15; Müssig (Anm. 14), S. 114. 
diesen Weg einschlagen, käme man zu dem wertungswidersprüchlichen Ergebnis, dass keine lebenslange Freiheitsstrafe verhängt werden könnte, sondern aufgrund der Regelung des $\S 52$ Abs. 2 StGB, der zufolge die Strafe dem Gesetz zu entnehmen ist, das die schwerste Strafe androht, gemäß § 38 Abs. 2 StGB nur die Höchststrafe von 15 Jahren unter strafschärfender Berücksichtigung der idealkonkurrierenden Körperverletzung. Diese Regelung ist jedoch wenig plausibel, weil sie das zusätzliche Unrecht, das in der Verletzung eines weiteren Rechtsguts liegt, unterschlägt. Es bedarf daher eigentlich einer allgemeinen Neuordnung der Konkurrenzen ${ }^{131}$, ohne die eine umfassende wertungswiderspruchsfreie Lösung nicht gefunden werden kann. Richtigerweise müsste auch bei Tateinheit eine Gesamtstrafe gebildet werden.

Ungeachtet dieser grundsätzlichen Probleme hat die Expertengruppe mit absoluter Mehrheit für die Beibehaltung, aber auch für eine Änderung dieses Mordmerkmals gestimmt. Mit jeweils relativer Mehrheit wurden folgende Beschlüsse gefasst: die Ersetzung der grausamen Tatbegehung durch „unter Zufügung erheblicher körperlicher oder seelischer Qualen“, durch „in qualvoller Weise“ sowie durch „qualvoll“. Jeweils soll die Gesinnungskomponente ausgeschlossen werden ${ }^{132}$. Letzteres wäre uneingeschränkt zu begrüßen. Ebenso soll das Mordmerkmal „mit gemeingefährlichen Mitteln“ nach Auffassung der Expertengruppe ohne Änderung beibehalten werden ${ }^{133}$. Dass diese Tatvariante als besonders gefährliche Art und Weise der Tatausführung zu qualifizieren ist, versteht sich von selbst ${ }^{134}$. Allerdings stellt sich dasselbe Problem wie bei der grausamen Begehungsweise, dass es sich um zusätzliches, im Wege der Konkurrenzenregelung $\mathrm{zu}$ berücksichtigendes Unrecht handelt. Nicht das Unrecht der einzelnen Tötung wird erhöht, sondern es tritt neben dieses Unrecht weiteres vorsätzliches Gefährdungsunrecht bezüglich weiterer Tatobjekte ${ }^{135}$. Der Gesetzgeber hat freilich bei den Brandstiftungsdelikten die Betroffenheit mehrerer Opfer als Qualifikationsgrund anerkannt. So begeht eine besonders schwere Brandstiftung gemäß § 306b Abs. 2 StGB, wer durch eine Brandstiftung nach $\S 306$ StGB oder § 306a StGB eine Gesundheitsschädigung einer großen Zahl von Menschen verursacht. Zudem irritiert an diesem Tatbestandsmerkmal, dass es bei einer schlichten Mehrfachtötung nicht erfüllt sein soll, dass also nur die Gefährdung

131 Vgl. Erb, ZStW 117 (2005), S. 37, 42, 66 ff., 74 ff.; Freund, GA 2005, 321, 325 f.

132 Beratungsergebnisse, in: Abschlussbericht (Anm. 4), S. 47.

133 Beratungsergebnisse, in: Abschlussbericht (Anm. 4), S. 47.

134 Neumann, in: NK StGB (Anm. 43), § 211 Rdn. 85.

135 Müssig (Anm. 14), S. 114; Grünewald, in: Abschlussbericht (Anm. 4), S. 477, 483; Mitsch, JR 2015, 122, 123. 
Unbeteiligter erfasst wird, deren Tötung vom Vorsatz des Täters nicht umfasst ist $^{136}$.

Eine erhöhte Tatgefährlichkeit wird auch bei den Mordmerkmalen der ersten und dritten Gruppe angenommen. So ist Rüping der Ansicht, dass beim Mord zur Befriedigung des Geschlechtstriebs sowie beim Mord aus Habgier jeweils weitere Rechtsgüter verletzt werden würden: die sexuelle Selbstbestimmung und das Vermögen wie insbesondere beim Raubmord ${ }^{137}$. Schon beim Mordmerkmal der Mordlust vermag Rüping jedoch kein weiteres Rechtsgut $\mathrm{zu}$ benennen. Und beim Mordmerkmal der niedrigen Beweggründe scheitert auch seiner eigenen Auffassung nach seine Strategie einer restriktiven Interpretation der Mordmerkmale ${ }^{138}$. Bei den Mordmerkmalen der dritten Gruppe läge bei der Ermöglichungsabsicht die Steigerung des Unrechts darin, dass die Tötung der Begehung kriminellen Unrechts und damit der Verletzung eines weiteren Rechtsguts dient ${ }^{139}$. Die Expertengruppe hat ohne Begründung empfohlen, dieses Mordmerkmal unverändert beizubehalten $^{140}$.

Das gleiche Votum hat die Expertengruppe bezüglich der Verdeckungsabsicht abgegeben. Die Mitglieder der Kommission haben die Auffassung vertreten, dass das Erfolgsunrecht der Tat deswegen erhöht werde, weil der Täter der Rechtswahrungsfunktion des Staates entgegenwirke und damit einen Grundwert des demokratischen Rechtsstaats angreife ${ }^{141}$. Ähnlich lautet die Auffassung eines Teils der Literatur, die sich darauf beruft, dass der Täter durch die Tötung des Opfers zugleich beabsichtige, in das Rechtsgut der Strafrechtspflege einzugreifen $^{142}$. Es bedarf an dieser Stelle keiner Darlegung, welche Konsequenzen diese rechtsgutsbezogene Auslegung für die Anwendung der betreffenden Mordmerkmale mit sich brächte. Es genügt der Hinweis, dass ihr Anwendungsbereich erheblich limitiert werden würde. $\mathrm{Zu}$ bezweifeln ist ohnehin, ob bei den Mordmerkmalen der ersten und dritten Gruppe dieser Erklärungsansatz auf eine wesentliche Steigerung des Unrechtsgehalts der Tat verweisen könnte ${ }^{143}$. In

136 Siehe dazu Schneider, in: MK (Anm. 74), § 211 Rdn. 122; Grünewald, in: Abschlussbericht (Anm. 4), S. 477, 483.

137 Rüping, JZ 1979, 617, 620.

138 Rüping, JZ 1979, 617, 620.

139 Rüping, JZ 1979, 617, 619; Sinn, in: SK StGB (Anm. 54), § 211 Rdn. 66; Eser/Stermberg-Lieben, in: Schönke/Schröder (Anm. 43), § 211 Rdn. 31.

140 Beratungsergebnisse, in: Abschlussbericht (Anm. 4), S. 46.

141 Beratungsergebnisse, in: Abschlussbericht (Anm. 4), S. $49 \mathrm{f}$.

142 Vgl. Rüping, JZ 1979, 617, 619; Lackner/Kühl (Anm. 43), § 211 Rdn. 12; Küper, JZ 1995, 1158; Sowada, JZ 2000, 1035; Geppert, Jura 2004, 243, 245; Otto, Grundkurs Strafrecht, 7. Aufl. 2005, § 4 Rdn. 48; ders., Jura 1994, 141, 151.

143 Kargl, StraFo 2001, 365, 366, 367, 373. 
vielen Fällen würde sich die gegen das weitere Rechtsgut gerichtete Tat lediglich im Vorbereitungsstadium befinden. Speziell beim Mordmerkmal der Verdeckungsabsicht stellt sich das Problem, dass sich der Täter häufig in einer Bedrängnissituation befinden wird, die seine Fähigkeit zu normgemäßen Verhalten verringert. Sofern dagegen eingewandt wird, dass sich der Täter diese Bedrängnissituation selbst zuzuschreiben habe ${ }^{144}$, wird zwar im Ansatz zu Recht eine Parallele zur Rechtsfigur der actio libera in causa gezogen; ihre Anwendung würde allerdings voraussetzen, dass das Vorverhalten tatsächlich rechtswidrig ist und sich der Täter dies nicht nur vorgestellt hat. Des Weiteren wäre Voraussetzung, dass der Täter die Tötung im Zeitpunkt des Vorverhaltens hätte vorhersehen müssen. Die Validität der Replik würde also eine weitere Beschneidung des Anwendungsbereichs dieses Mordmerkmals zur Folge haben. Entscheidend ist jedoch der folgende Einwand: Der Täter könnte sich gegenüber dem Staat auf das Selbstbegünstigungsprinzip berufen. Das Selbstbegünstigungsprinzip mindert zwar nicht das Unrecht der Tötung. Es wäre aber im Hinblick auf die Wertung des $\S 258$ StGB wertungswidersprüchlich, dem Täter den Eingriff in die Strafrechtspflege unrechtssteigernd anzulasten. Damit soll nicht in Abrede gestellt werden, dass ein Zeuge aufgrund der staatlichen Inanspruchnahme besonders schutzwürdig ist. Aber dieser Umstand begründet für sich allein noch kein erhöhtes Unrecht ${ }^{145}$. Es sei hinzugefügt, dass die Formel der Rechtsprechung, der Täter verknüpfte Unrecht mit weiterem Unrecht ${ }^{146}$, gleichermaßen völlig ungeeignet ist, eine Unrechtssteigerung zu begründen.

\section{cc) Die Berücksichtigung der Sozialgefährlichkeit der Tat}

Ein weiterer Ansatz stützt die Höchststrafwürdigkeit des Mordes auf die Sozialgefährlichkeit bzw. die Gemeinschaftsbedrohlichkeit der Tat ${ }^{147}$. Schon Eser hatte im Sinne der Integrationsprävention auf die Bedeutung aufmerksam gemacht, die dem Erhalt des Vertrauens der Allgemeinheit in die Bestands- und Durchsetzungskraft der Rechtsordnung gerade bei den Tötungstatbeständen zukommt. Aufgrund sozialpsychologischer Mechanismen sei ein qualifiziertes Präventionsbedürfnis bei Tötungen nicht zu leugnen, die besonders geeignet seien, Angst und Unsicherheit $\mathrm{zu}$ verbreiten ${ }^{148}$. Der Alternativentwurf-Leben aus dem Jahr 2008 hatte diese Begründung aufgegriffen und der Bedrohung der Lebenssicher-

144 Vgl. Beratungsergebnisse, in: Abschlussbericht (Anm. 4), S. 49.

145 Siehe schon ausführlich dazu Haas, Festschrift für Weber, S. 235, 247.

146 BGHSt. 42, 8, 9.

147 So Schneider, in: MK (Anm. 74), § 211 Rdn. 18; ders., in: Abschlussbericht (Anm. 4), S. 830 ff.

148 Eser, Gutachten zum 53. Deutschen Juristentag, 1980, D $166 \mathrm{ff}$. 
heit der Allgemeinheit eine unrechtserhöhende Wirkung zuerkannt, die dazu berechtigen soll, der zu erwartenden besonderen Rechtserschütterung im Wege der Integrationsprävention zu begegnen ${ }^{149}$. Ganz ähnlich stützt Schneider den Mordtatbestand auf die Integrationsprävention, der er im Vergleich zur Abschreckung das umfassendere Erklärungspotential zubilligt. Bestimmte Tötungen würden als besonders gemeinschaftsbedrohend wahrgenommen und daher das Sicherheitsgefühl der Allgemeinheit in besonderem Maße beeinträchtigen ${ }^{150}$.

Dies soll evidentermaßen bei gemeingefährlichen Tötungen der Fall sein, bei denen eine Vielzahl von Menschenleben in Gefahr geraten würde ${ }^{151}$. Die besondere Sozialgefährlichkeit des Täters löse eine sozialpsychologisch vermittelte Verunsicherung der Allgemeinheit aus, da jedermann zufällig in den Einwirkungsbereich eines derartigen Tötungsverbrechens geraten könne, ohne die Chance zu haben, sich auf die ihm drohende Gefahr einzustellen und darauf $\mathrm{zu}$ reagieren $^{152}$. Bei grausamen Tötungen würden jegliche Hemmschwellen gegenüber der Verletzung von Leib und Leben fehlen. Die dadurch hervorgerufene Kriminalitätsfurcht rechtfertige daher die Höchststrafe ${ }^{153}$. Das qualvolle Peinigen von Menschen sei besonders gefährlich, weil dadurch der Abbau von Hemmschwellen gegenüber massiver Gewaltanwendung gefördert werden könne ${ }^{154}$. Der Strafgrund der Integrationsprävention soll jedoch auch bei den subjektiven Mordmerkmalen die Rechtsfolge tragen. Zum einen meint Schneider, dass die Sozialgefährlichkeit durch die Instrumentalisierung des Opfers, durch die Grundlosigkeit bzw. Anlasslosigkeit der Tötung, durch die Alltäglichkeit des Tötungsmotivs, durch die Rücksichtslosigkeit des Täters oder durch die hochgradige Geringschätzung menschlichen Lebens erhöht werde ${ }^{155}$. Zum anderen beruft sich Schneider darauf, dass die beliebige Austauschbarkeit des Opfers eine besonders gravierende Störung der sozialen Ordnung zur Folge habe ${ }^{156}$. Ein

149 AE-Leben, GA 2008, 199, 221.

150 Schneider, in: MK (Anm. 74), § 211 Rdn. 18; ebenso schon Woesner, NJW 1979, 1025, 1027.

151 Schneider, in: MK (Anm. 74), § 211 Rdn. 18.

152 Schneider, in: MK (Anm. 74), § 211 Rdn. 121; vgl. AE-Leben, GA 2008, 193, 225: Bedrohung der Lebenssicherheit der Allgemeinheit durch den gefährlichen Abbau des Tötungstabus.

153 Schneider, in: MK (Anm. 74), § 211 Rdn. 18.

154 Schneider, in: MK (Anm. 74), § 211 Rn 130.

155 Schneider, in: MK (Anm. 74), § 211 Rdn. 19, 52, 53, 61, 71, 250.

156 Schneider, in: MK (Anm. 74), § 211 Rdn. 19, 52, 53, 61; vgl. AE-Leben, GA 2008, 193, 234, 238, 240: Wirkung, die über die einzelne Tötung hinausgehe, wenn jeder Bürger Opfer dieser Tat werden könne. 
Verstoß gegen das Schuldprinzip sei zu verneinen, da auch das Schuldprinzip generalpräventive Elemente aufweise ${ }^{157}$.

Eine tatsächliche Gefährdung der Lebenssicherheit der Allgemeinheit, die unrechtssteigernd $\mathrm{zu}$ Buche schlagen könnte, wird durch den einzelnen Mord in der Regel nicht verursacht. Mit dem Verweis auf die Sozialgefährlichkeit kann daher nur der Umstand gemeint sein, dass bestimmte Tötungen eine massive Verunsicherung in der Bevölkerung auslösen. Auslöser des Bedrohungsgefühls der Allgemeinheit ist also die Furcht vor weiteren Straftaten, deren Begehung sich der Täter aber selbst im wenig wahrscheinlichen Fall einer „Infektionswirkung“ nicht zurechnen lassen müsste ${ }^{158}$. Ungeachtet dessen kann die Beseitigung der Kriminalitätsfurcht nur gelingen, wenn die Bevölkerung glaubt, dass das Strafrecht einen wirksamen Beitrag zu ihrem Schutz leisten kann. Insofern die Integrationsprävention die bezweckte Stärkung der Rechtstreue auf das Vertrauen der Gesellschaft stützt, dass sich das Recht gegenüber dem Unrecht durchsetzt, ist die positive Generalprävention aber nichts anderes als ein empirisches Derivat der im nächsten Abschnitt thematisierten negativen Generalprävention, das auf die Vorstellungen der Rechtsgemeinschaft rekurriert.

Ähnliches gilt für die Erschütterung der sozialen Ordnung, auf die sich - wie oben dargelegt - Schneider beruft. Gemeint ist damit offenbar eine massive Störung des Rechtsfriedens. Die Stärkung der Rechtstreue der Bevölkerung durch die Befriedung der Rechtsgemeinschaft - das heißt durch die Beruhigung ihres gekränkten Rechtsbewusstseins - ist jedoch nichts anderes als ein empirisches Derivat des Schuldausgleichs ${ }^{159}$. Und deshalb kann auch die Erschütterung des Rechtsbewusstseins kein Grund sein, eine Strafe zu verhängen, die über die vom Täter verwirklichte Schuld hinausreicht ${ }^{160}$. Nur in dem Maße, in dem der Täter Schuld verwirklicht hat, ist das Gefühl der Kränkung seitens der Rechtsgemeinschaft auch berechtigt. Die Rechtsfriedensstörung fügt der Schuld daher keinen weiteren Strafwürdigkeitsgehalt hinzu. Das faktische Ausmaß der Rechtsfriedensstörung kann daher nur innerhalb des Schuldspielraums Berücksichtigung finden. Ganz allgemein ist zu bemerken, dass im Namen der Stabilisierung der Normgeltung nicht schon die faktische Erwartungshaltung der Gesellschaft ein hinreichender Strafgrund ist. Sie muss sich vielmehr - wie bei jedem anderen Grundrechtseingriff auch - dem Verurteilten gegenüber legitimieren lassen. Die Rationalitätsansprüche im Strafrecht niedriger zu taxieren als in anderen Rechtsgebieten, ist angesichts der Intensität des Grundrechtseingriffs mehr als fragwür-

157 Schneider, in: MK (Anm. 74), § 211 Rdn. 21.

158 Merkel, in: Abschlussbericht (Anm. 4), S. 658, 661; ders., ZIS 2015, 429, 430.

159 Siehe Haas, Strafbegriff, Staatsverständnis und Prozessstruktur (Anm. 76), S. $268 \mathrm{ff}$.

160 Vgl. Merkel, ZIS 2015, 429, 432, zum Verhältnis von Sozialgefährlichkeit und Schuld. 
dig. Die Vernunft ist unteilbar. Zu Recht hat daher die Expertengruppe dem Leitprinzip der besonderen Sozialschädlichkeit mit relativer Mehrheit eine Absage erteilt. Dem Kriterium der Bedrohung der Lebenssicherheit der Allgemeinheit wurde sogar mit absoluter Mehrheit die Gefolgschaft versagt ${ }^{161}$.

\section{c) Das Leitprinzip der Tätergefährlichkeit}

\section{aa) Generalpräventive Erklärungsansätze}

Wenn ein Teil der Literatur auf die Tätergefährlichkeit ${ }^{162}$ verweist, scheint damit die Gefahr der Begehung weiterer Straftaten durch den konkreten Täter gemeint zu sein. Dies ist jedoch nicht ausnahmslos der Fall. Gemeint ist vielmehr vereinzelt die erhöhte Gefahr einer Tatbegehung durch potentielle Täter. Die Mordmerkmale werden also mit Hilfe der negativen Generalprävention legitimiert. So beruft man sich auf die abschreckende Wirkung der lebenslangen Freiheitsstrafe insbesondere bei Mordmerkmalen, die auf habituell tötungsfördernden Einstellungen beruhen wie bei der Gewinnsucht oder Triebbefriedigung. Des Weiteren soll ein besonderer Präventionsbedarf bei ubiquitär anzutreffenden Alltagsinteressen bestehen ${ }^{163}$. Sodann wird auf die Abschreckung in den Fällen konstellativer Gefährlichkeit gesetzt, in denen sich der Täter sehenden Auges in eine tötungsfördernde Situation begibt wie insbesondere bei der Verdeckungsabsicht. Es soll insoweit aus Gründen des Rechtsgüterschutzes einer generalpräventiven Einwirkung auf tatgeneigte Täter bedürfen ${ }^{164}$. Auch das Bundesverfassungsgericht hat in seinem die lebenslange Freiheitsstrafe betreffenden Urteil die Generalprävention als Legitimationsgrund für das Mordmerkmal der Verdeckungsabsicht anerkannt ${ }^{165}$. Gegen diesen Begründungsversuch ist jedoch einzuwenden, dass der Strafrahmensprung von Totschlag zu Mord ohne Verstoß gegen das Schuldprinzip nicht mehr zu rechtfertigen ist ${ }^{166}$. Diesen Punkt hat das Bundesverfassungsgericht leider nicht thematisiert. Schließlich ist an die Erkenntnis der kriminologischen Forschung zu erinnern, dass eher die Entdeckungswahrschein-

161 Beratungsergebnisse, in: Abschlussbericht (Anm. 4), S. $29 \mathrm{f}$.

162 So schon Rieß, NJW 1968, 628, 629; Rüping, JZ 1979, 617, 619: apokrypher Strafgrund des Mordes; Schünemann, Festschrift für Bockelmann, S. 117, 132; Woesner, NJW 1980, 1136, 1139; de lege ferenda Beckmann, GA 1981, 337, $357 \mathrm{ff}$.

163 Schneider, in: MK (Anm. 74), § 211 Rdn. 18; vgl. auch Jakobs, NJW 1980, 489, 490, der auf die Gefahr des Umsichgreifens solcher Taten auch in weiteren Fallgruppen verweist.

164 So Neumann, in: NK StGB (Anm. 43), § 211 Rdn. 98; Wessels/Hettinger, Strafrecht Bes. Teil 1 (Anm. 43), Rdn. 123; Rengier, Strafrecht Bes. Teil II (Anm. 45), § 4 Rdn. 52.

165 BVerfGE 45, $187 \mathrm{ff}$.

166 Vgl. Albrecht, JZ 1982, 697, 702. 
lichkeit als die Strafhöhe generalpräventiv wirksam ist ${ }^{167}$. Auch dies spricht gegen die Fundierung des $\S 211$ StGB durch dieses Leitprinzip.

\section{bb) Spezialpräventive Erklärungsansätze}

Vor allem werden jedoch spezialpräventive Ansätze vertreten. So hat insbesondere Arzt die Mordmerkmale mit der Gefährlichkeit des Täters legitimiert. Die lebenslange Freiheitsstrafe ist seines Erachtens zur Sühne der Tatschuld nicht erforderlich. Der Mord weise zudem gegenüber dem Totschlag weder im Unrechts-, noch im Schuldgehalt einen so gravierenden Unterschied auf, dass der Strafrahmensprung verständlich $\operatorname{se}^{168}$. Angesichts der Bedeutung des Rechtsguts „Leben“ übernehme die lebenslange Freiheitsstrafe die Funktion der Sicherungsverwahrung, ohne dass die bei ihr vorausgesetzten Kriterien vorliegen müssten $^{169}$. So wie in der Mordstrafe die Sicherungsmaßregel stecke, so sei in dem Mordtatbestand die besondere Tätergefährlichkeit enthalten ${ }^{170}$. Die Mordmerkmale sind daher seines Erachtens daraufhin zu untersuchen, ob ihre Verwirklichung eine Wiederholungs- bzw. Rückfallgefahr indiziert oder nicht ${ }^{171}$. Arzt bejaht dies für die Mordmerkmale der Mordlust, der Befriedigung des Geschlechtstriebes sowie im Falle des Raubmörders bei der Habgier. Schließlich bejaht Arzt beim Mord zur Ermöglichung einer Straftat eine häufige Rückfallgefahr. Als neutral stuft er hingegen die Mordmerkmale des niedrigen Beweggrundes, der Heimtücke, der Grausamkeit und der gemeingefährlichen Mittel $\operatorname{ein}^{172}$.

Der Legitimationsansatz von Arzt ist weder de lege lata noch de lege ferenda akzeptabel. De lege lata ist die Verschmelzung von Strafe und Maßregel nicht mit der Zweispurigkeit unseres Sanktionssystems zu vereinbaren. Es wäre zudem nicht begründbar, warum bei einer Tötung die Anwendungsvoraussetzungen und die Sicherungsvorkehrungen der Sicherungsverwahrung unterlaufen werden dürften ${ }^{173}$. Zudem müsste bei dem Ansatz von Arzt eigentlich auf eine Verurteilung nach $\S 211$ StGB verzichtet werden, wenn im Einzelfall eine konkrete Wieder-

167 Albrecht, JZ1982, 697, 703.

168 Arzt, ZStW 83 (1971), S. 1, 12ff., 19ff.; ders., in: Jescheck/Triffterer (Hrsg.), Ist die lebenslange Freiheitsstrafe verfassungswidrig?, 1978, S. 141, 151; ders., in: Göppinger/Bresser (Hrsg.), Tötungsdelikte, S. 49, $54 \mathrm{ff}$.

169 Arzt, in: Göppinger/Bresser (Hrsg.) (Anm. 168), S. 49, 54.

170 Arzt, in: Jescheck/Triffterer (Hrsg.) (Anm. 168), S. 141, 151.

171 So auch Schünemann, Festschrift für Bockelmann, S. 117, 132.

172 Arzt, ZStW 83 (1971), S. 1, 19 f.; ebenso Gössel, DRiZ 1980, 281, 285.

173 Eser (Anm. 148), D 166; Albrecht, JZ 1982, 697, 702. 
holungsgefahr nicht festgestellt werden könnte. Schließlich fehlen für die postulierte Korrelation zwischen einzelnen Mordmerkmalen und Tätergefährlichkeit empirisch valide Kriterien ${ }^{174}$. Es wird daher bezweifelt, dass die Mordmerkmale eine Wiederholungsgefahr indizieren, die über das allgemeine Rückfallrisiko bei allen vorsätzlichen Tötungen hinausreicht ${ }^{175}$. Zudem wird darauf hingewiesen, dass Mörder eher selten rückfällig werden ${ }^{176}$.

Auch de lege ferenda steht der Einebnung von Strafe und Maßregel das verfassungsrechtliche Schuldprinzip entgegen ${ }^{177}$. Für die Strafe ist die Tatschuld Grund der Sanktion. Für die Maßregel ist die Tat nur Indikator für die Gefährlichkeit des Täters. Beide Sanktionen sind daher nicht auf einen Nenner zu bringen. Sie sind inkompatibel, so dass sich eine subkutane Transformation des Tatstrafrechts in ein auf Gefährlichkeitserwägungen gegründetes Täterstrafrecht verbietet. Es ist allerdings Arzt zuzugestehen, dass es sein Bestreben gewesen ist, angesichts des Faktums der lebenslangen Freiheitsstrafe dieser nachträglich einen berechtigten Anwendungsbereich zu verschaffen ${ }^{178}$. Und vielleicht steckt in seiner Überlegung ungeachtet aller rechtlichen Bedenken faktisch doch im Kern ein Stück Wahrheit. Darauf wird weiter unten noch einmal einzugehen sein. Trotz dieses Zugeständnisses ist der Expertengruppe zu folgen, insofern sie das Leitprinzip der Tätergefährlichkeit mit relativer Mehrheit abgelehnt hat ${ }^{179}$.

\section{c) Fazit}

Es kann festgehalten werden, dass bei Beachtung eines strikten Tatbezugs sich die rationale Bedeutung der Mordmerkmale der niedrigen Beweggründe darin erschöpft, das Fehlen privilegierender unrechts- oder schuldmindernder Umstände zu indizieren. In der Sache wird aufgrund dieser Merkmale de lege lata implizit anerkannt, dass schon das Tötungsunrecht als solches ohne das Vorliegen strafschärfender Umstände ein hinreichender Legitimationsgrund ist, zu Lasten des

174 Rengier, ZStW 92 (1980), S. 459, 471; Albrecht, JZ 1982, 697, 702; Grünewald (Anm. 33), S. 53; Heine (Anm. 58), S. $199 \mathrm{ff}$.

175 Hörnle, in: Festschrift für Frisch, S. 653, 657.

176 Schneider, in: MK (Anm. 74), § 211 Rdn. 17.

177 Albrecht, JZ 1982, 697, 702; vgl. die Ansicht von Hilgendorf, in: Arzt/Weber/Heinrich/Hilgendorf, Strafrecht Bes. Teil (Anm. 55), § 2 Rdn. 21, dass sich die Gefährlichkeitslösung mit dem derzeitigen engen Verständnis des Tatschuldgedankens nicht vereinbaren lasse; ablehnend auch Merkel, ZIS 2015, 429, 430.

178 Arzt, ZStW 83 (1971), S. 1, 11, 14; ders., in: Jescheck/Triffterer (Hrsg.) (Anm. 168), S. 141, 151.

179 Beratungsergebnisse, in: Abschlussbericht (Anm. 4), S. 29. 
Täters die Höchststrafe zu verhängen. Die gesinnungsstrafrechtlichen Elemente sollten daher elemiminiert werden ${ }^{180}$. Dies gilt insbesondere dann, wenn man auf der Ausgestaltung des Mordes als Qualifikationstatbestand beharrt. Die Mehrheit der Expertengruppe hat diese Zusammenhänge verkannt und die Anzahl der Gesinnungsmerkmale sogar noch vergrößert ${ }^{181}$.

Bei den Mordmerkmalen der zweiten Gruppe wird das Tötungsunrecht selbst nicht erhöht. Es tritt vielmehr zu dem Tötungsunrecht weiteres Unrecht. Dies führt zu dem Wertungswiderspruch, dass im Unterschied zu den niedrigen Beweggründen erst durch dieses zusätzliche Unrecht die Tat die Auferlegung der lebenslangen Freiheitsstrafe auslöst. In einem dogmatisch kohärent systematisierten Strafrecht müsste zudem dieses zusätzliche Unrecht eigentlich in einer allgemeinen, in sich stimmigen Regelung der Konkurrenzen angemessene Berücksichtigung finden. Solange es an einer derartigen Regelung fehlt, scheint - so könnte man meinen - die Erfassung dieses zusätzlichen Unrechts durch Qualifikationstatbestände tolerabel zu sein. Man darf jedoch nicht außer Acht lassen, dass bei einer sektoralen Regelung unvermeidbare Wertungswidersprüche zur allgemeinen Regelung der Konkurrenzen auftreten würden. Schließlich sollte man sich bewusst machen, dass dieses zusätzliche Unrecht allenfalls in Ausnahmefällen ein derartiges Gewicht hat, den Strafrahmensprung von § 212 Abs. 1 StGB zu $§ 211$ StGB legitimieren zu können. Das Tötungsunrecht selbst ist nur bedingt steigerungsfähig ${ }^{182}$. Man könnte zwar das Unrecht mit Hilfe des Kriteriums der Tatgefährlichkeit quantitativ abschichten. Angesichts eines Kontinuums gradueller Steigerungen der Tatgefährlichkeit ist das Heimtückemerkmal jedoch nicht - wie gezeigt - geeignet, eine schlüssige Grenze zwischen Mord und Totschlag $\mathrm{zu}$ ziehen. Eine relative hohe Erfolgswahrscheinlichkeit wird bei Tötungen ohnehin die Regel sein. Theoretisch denkbar wäre es zudem, an besondere Pflichtenstellungen anzuknüpfen und den Mord insoweit als eine Art Sonderdelikt auszugestalten, das zum Beispiel bei Tötungen von Verwandten und Schutzbefohlenen eingreifen könnte. Der Gesetzgeber hat jedoch einen derartigen Straftatbestand nicht geschaffen ${ }^{183}$.

180 Ebenso im Ergebnis Rüping, JZ 1979, 617, 620; Kargl, StaFo 2001, 365, 375; Hirsch, Festschrift für Rissing-van Saan, 2011, S. 229, 230.

181 Für einen Katalog fest definierter Motivtypen Mitsch, JR 2015, 122, 123.

182 So schon Arzt, ZStW 83 (1971), S. 1, 12; Eser (Anm. 148), D 37; Beckmann, GA 1981, 335, 350.

183 Siehe dazu Grünewald (Anm. 33), S. $178 \mathrm{ff}$. 


\section{Die Rechtsfolge der absolut angedrohten lebenslangen Freiheitsstrafe}

\section{a) Die lebenslange Freiheitsstrafe als verfassungsrechtlich problematische Strafsanktion}

Die Reform der Tötungsdelikte wäre eigentlich ein Anlass, die lebenslange Freiheitsstrafe als solche auf den Prüfstand zu stellen. Man kann sogar der Auffassung sein, dass es vier Jahrzehnte nach der grundlegenden Entscheidung des Bundesverfassungsgerichts zur Verfassungsmäßigkeit der lebenslangen Freiheitsstrafe ${ }^{184}$ dringend an der Zeit wäre, sich über diese Sanktion erneut Rechenschaft abzulegen ${ }^{185}$. Auch die Expertengruppe hat sich die Frage gestellt, ob am Konzept der lebenslangen Freiheitsstrafe festzuhalten sei. Es bestehen Bedenken, dass es sich um eine an sich unbestimmte, genau genommen grenzenlose Strafe handelt, die nicht durch eine entsprechende Schuld legitimiert werden kann $^{186}$. So könnte man einen Vergleich zur Vermögensstrafe ziehen: Diese hatte das Bundesverfassungsgericht für verfassungswidrig erklärt, weil der Gesetzgeber darauf verzichtet habe, eine fallunabhängige, abstrakte Belastungsobergrenze festzulegen ${ }^{187}$. Ebenso wie bei der Vermögensstrafe die Höhe der Strafe durch die zufällige Größe des Vermögens im Einzelfall determiniert wird, wird bei der lebenslangen Freiheitsstrafe die Höhe der Strafe durch die zufällige Dauer der verbleibenden Lebenszeit bestimmt. Diese Bedenken wurden zwar zur Kenntnis genommen. Für die Beibehaltung der lebenslangen Freiheitsstrafe wurde jedoch geltend gemacht, dass sie in ihrer Symbolfunktion als Ersatz für die Todesstrafe eine wichtige integrative Aufgabe erfülle. Sie bekräftige den absoluten Geltungsanspruch des Tötungstabus und berücksichtige die Vergeltungserwartungen der Allgemeinheit ${ }^{188}$. Ohne Gegenstimme wurde daher mit sehr deutlicher absoluter Mehrheit dafür plädiert, an der lebenslangen Freiheitsstrafe für höchststrafwürdige Tötungen festzuhalten ${ }^{189}$. Das faktische Vergeltungsverlangen der Bevölkerung ist jedoch - dies sei an dieser Stelle noch

184 BVerfGE 45, $187 \mathrm{ff}$.

185 So Kinzig, in: Abschlussbericht (Anm. 4), S. 529.

186 Vgl. Radtke, in: Münchener Kommentar, StGB, Band 2, 2. Aufl. 2012), § 38 Rdn. 8; zweifelnd Bock/Mährlein, ZRP 1997, 376, 380; ablehnend Kett-Straub (Anm. 105), S. 47, mit dem alles andere als überzeugenden, weil zirkulären Argument, dass die Unbestimmtheit eben notwendige Folge der Verurteilung zu einer lebenslangen Freiheitsstrafe sei.

187 BVerfGE 105, 135, $163 \mathrm{f}$.

188 Vgl. Schneider, Festschrift für Widmaier, 2008, S. 741, 759: lebenslange Freiheitsstrafe als Leitwährung des Strafrechts; Kett-Straub (Anm. 105), S. 13, 30.

189 Beratungsergebnisse, in: Abschlussbericht (Anm. 4), S. 53 f. 
einmal betont - kein hinreichender Grund, diese Sanktion weiterhin zu verhängen. Auch ein Straftäter bleibt Mitglied der Rechtsgemeinschaft, dem gegenüber Eingriffe in Grundrechte der Legitimation bedürfen. Man könnte argumentieren, dass die lebenslange Freiheitsstrafe den bürgerlichen oder sozialen Tod des verurteilten Täters zur Folge habe ${ }^{190}$. Eine ernsthaftere Auseinandersetzung mit dieser Problematik wäre daher an sich wünschenswert gewesen, auch wenn zuzugestehen ist, dass eine (völlige) Abschaffung der lebenslangen Freiheitsstrafe gegenwärtig politisch äußerst unrealistisch ist ${ }^{191}$. Zumindest wäre jedoch zu bedenken gewesen, ob man nicht ihre Androhung hätte begrenzen müssen, um die weiter unten noch darzustellenden Unstimmigkeiten der Vollstreckungslösung des $\S 57$ a StGB zu vermeiden.

\section{b) Die absolute Androhung der lebenslangen Freiheitsstrafe}

Ein weiterer, vielfach geäußerter Kritikpunkt betrifft die absolute Androhung der lebenslangen Freiheitsstrafe, die keinen Raum für die Berücksichtigung strafmildernder Umstände lässt ${ }^{192}$. Die absolute Androhung der lebenslangen Freiheitsstrafe hat zudem - dieser Punkt sei zumindest nochmals erwähnt - eine große Sanktionskluft zu § 212 Abs. 1 StGB zur Folge ${ }^{193}$, die selbst von den unrechtserhöhenden Mordmerkmalen nicht oder kaum getragen wird. Bei einem Totschlag nach $\S 212$ Abs. 1 StGB kann auf Freiheitsstrafe von fünf bis fünfzehn Jahren erkannt werden. Überhaupt kein Sanktionsunterschied besteht hingegen zum besonders schweren Totschlag nach § $212 \mathrm{Abs.} 2 \mathrm{StGB}$, der in der Praxis kaum eine Rolle spielt. Dies ist kein Zufall, da die Umstände, die die besondere Schwere der Tat begründen können, regelmäßig zur Erfüllung des Mordtatbestandes führen ${ }^{194}$.

Die Tätertypenlehre hatte immerhin gesetzestechnisch die Option eröffnet, den Tatbestand des Mordes bei Vorliegen außergewöhnlicher unrechts- und schuldmindernder Umstände auszuschließen. Die rechtsstaatlich motivierte $\mathrm{Zu}$ rückweisung dieser Lehre nach dem Zweiten Weltkrieg hat daher paradoxerweise

190 Hilgendorf, in: Arzt/Weber/Heinrich/Hilgendorf, Strafrecht Bes. Teil (Anm. 55), § 2 Rdn. 19; Mandla, Festschrift für Rössner, 2015, S. 845, 857.

191 So auch die Einschätzung von Saliger, ZIS 2015, 600, 603.

192 Gössel, DRiZ 1980, 281, 288; Heine (Anm. 58), S. 282; Kelker (Anm. 26), S. 613; AE-Leben, GA 2008, 193, 196; Mitsch, JR 2015, 122. 130; Saliger, ZIS 2015, 600, 602.

193 AE-Leben, GA 2008, 193, 195; Hilgendorf, in: Arzt/Weber/Heinrich/Hilgendorf, Strafrecht Bes. Teil (Anm. 55), § 2 Rdn. 23; Deckers/Fischer/König/Bernsmann, NStZ 2014, 9, 15; Mitsch, JR 2015, 122, 124, 130.

194 Deckers/Fischer/König/Bernsmann, NStZ 2014, 9, 15. 
den Tatbestand verschärft ${ }^{195}$. Der Diagnose von Mitsch, dass die Architekten des $\S 211$ StGB - anders als bei $\S 212$ Abs. 2 StGB und damit unter Verstoß gegen den Gleichheitsgrundsatz - kein Einfallstor für die Berücksichtigung mildernder Umstände in das Tatbestandsgebäude eingebaut hätten ${ }^{196}$, ist zuzustimmen. So bietet insbesondere die Heimtücke keine Möglichkeit, etwaige Unrechts- oder Schuldminderungen zu erfassen ${ }^{197}$. Eine Ausnahme bildet nur der Oberbegriff der niedrigen Beweggründe, weil bei diesem Mordmerkmal im Unterschied $\mathrm{zu}$ den anderen Mordmerkmalen eine Gesamtwürdigung vorzunehmen ist ${ }^{198}$. Beim Mordmerkmal der Mordlust, das eher eine psychopathologische Disposition indiziert $^{199}$, bedarf es einer Überschreitung der Schwelle des $§ 21$ StGB, um die Option für eine Strafmilderung zu gewinnen ${ }^{200}$.

Ungeachtet dessen hat das Bundesverfassungsgericht die Verfassungsmäßigkeit des $§ 211$ StGB bestätigt und nur eine verfassungskonforme Auslegung des Tatbestandes gefordert, die konkrete Umsetzung dieser Vorgaben aber der Rechtsprechung überlassen. Es sei Aufgabe des Bundesgerichtshofs, darüber zu finden, ob die restriktive Interpretation anhand einer engeren Auslegung der einzelnen Mordmerkmale oder anhand der Einführung einer Generalklausel der besonderen Verwerflichkeit erfolgen solle ${ }^{201}$. Es ist allerdings gegen die Entscheidung des Bundesverfassungsgerichts einzuwenden, dass eine restriktive, dem Verhältnismäßigkeitsgrundsatz Rechnung tragende Handhabung des § 211 StGB nicht mehr im Wege einer verfassungskonformen Auslegung des Tatbestandes zu erreichen ist, weil die unrechts- und schuldmindernden Umstände nicht konstitutiver Bestandteil der Begriffe sind, die die tatbestandlichen Voraussetzungen der Norm umschreiben ${ }^{202}$. Die unrechts- und schuldmindernden Aspekte werden gleichsam von außen an den Tatbestand und seine Merkmale herangetragen.

Um ein Beispiel zu nennen: Ob bei einer Mitleidstötung die Verwirklichung eines Heimtückemordes verneint wird, weil im Rahmen einer negativen Typenkorrektur aufgrund einer Gesamtwürdigung von Tat und Täter die besondere

195 Darauf hat schon Rieß, NJW 1968, 628, 629, aufmerksam gemacht; ebenso Beck, ZIS 2016, 10, 14.

196 Mitsch, JZ 2008, 336, 338; AE-Leben, GA 2008, 193, 195; vgl. auch Hilgendorf, in: Arzt/Weber/ Heinrich/Hilgendorf, Strafrecht Bes. Teil (Anm. 55), § 2 Rdn. 23: fehlende Aufweichung des Mordtatbestandes.

197 Vgl. Grünewald (Anm. 33), S. 139; zu dieser Problematik bei den anderen Mordmerkmalen Beckmann, GA 1981, 337, 339f., 343.

198 Mitsch, JZ 2008, 336, 339.

199 Woesner, NJW 1980, 1336, 1337; Kargl, StraFo 2001, 365, 366.

200 Schneider, in: MK (Anm. 74), § 211 Rdn. 52.

201 BVerfGE 45, $187 \mathrm{ff}$.

202 Vgl. Gössel, DRiZ 1980, 281, 288. 
Verwerflichkeit der Tat ausnahmsweise ausgeschlossen wird oder weil dem als Ausnutzen der Arg- und Wehrlosigkeit definierten Heimtückemerkmal das Merkmal der feindlichen Willensrichtung nachträglich einschränkend implementiert wird, macht weder materiell-rechtlich noch methodisch einen wesentlichen Unterschied $^{203}$. Zwar wird der Lehre von der negativen Typenkorrektur ${ }^{204}$ von der Rechtsprechung zu Recht vorgeworfen, von generalklauselartiger Weite zu sein und infolgedessen die Berechenbarkeit und Gleichmäßigkeit der die Tatbestandsfrage betreffenden Rechtsanwendung in Frage zu stellen. $\mathrm{Zu}$ Recht wird auch die Ungewissheit moniert, wie im Einzelfall die nur noch indizielle Bedeutung eines Mordmerkmals im Rahmen der Gesamtwürdigung zu veranschlagen ist, und die Abhängigkeit von subjektiven Erwägungen gerügt ${ }^{205}$. Nicht zu bezweifeln ist zudem die Richtigkeit des in der Literatur erhobenen Vorwurfs, dass eine regelgebundene Entscheidung durch einen moralischen Wertungsakt des Richters ersetzt werde ${ }^{206}$. Die Kritik übersieht jedoch, dass die bemängelte Rechtsunsicherheit - die dem Mordmerkmal der niedrigen Beweggründe nach herrschendem Verständnis ohnehin immanent ist - bei dem alternativen Vorgehen einer restriktiven Interpretation der einzelnen Mordmerkmale ebenso auftreten würde. Denn die Einbeziehung der feindlichen Willensrichtung in das Definiens der Heimtücke ergibt sich nicht aus dem gängigen Auslegungskanon, sondern gleichermaßen aus einer Wertentscheidung des Rechtsanwenders. Damit soll nicht für die Lehre von der negativen Typenkorrektur plädiert werden. Es soll vielmehr begründet werden, warum es vorzugswürdig gewesen wäre, wenn das Bundesverfassungsgericht $\S 211$ StGB wegen Verstoßes gegen das Schuldprinzip bzw. den Verhältnismäßigkeitsgrundsatz für verfassungswidrig erklärt hätte ${ }^{207}$. Der Tatbestand bietet in seiner heutigen Ausgestaltung keine Legitimationsgrundlage für die absolute Androhung der lebenslangen Freiheitsstrafe $^{208}$. Die völlige Verlagerung der Eingrenzung des Tatbestandes auf den Rechtsanwender ist auch im Hinblick auf den Gewaltenteilungsgrundsatz fragwürdig ${ }^{209}$.

203 Vgl. Sotelsek, Zur Quantifizierung von Unrecht und Schuld bei vorsätzlichen Tötungen, 2012, S. 171.

204 Geilen, JR 1980, 309f.; Saliger ZStW 109 (1997), S. 332ff.; Eser/Sternberg-Lieben, in: Schönke/ Schröder (Anm. 43), § 211 Rdn. 10; Sinn, in: SK StGB (Anm. 54), § 211 Rdn. 8.

205 BGHSt. (GS) 30, 105, 115.

206 Neumann, in: NK StGB (Anm. 43), § 211 Rdn. 47.

207 Für Verfassungswidrigkeit des § 211 StGB auch Mitsch, JZ 2008, $336 \mathrm{ff}$.

208 Deckers/Fischer/König/Bernsmann, NStZ 2014, 9, 15.

209 So Kargl, StraFo 2001, 365, 369. 
Es ist insbesondere beim Mordmerkmal der Heimtücke der Rechtsprechung bisher nicht gelungen, die Vorgaben des Bundesverfassungsgerichts in einer konsistenten Weise umzusetzen ${ }^{210}$. Ausschließlich beim Mordmerkmal der Heimtücke hat der Bundesgerichtshof nicht - wie vom Bundesverfassungsgericht gefordert - den Tatbestand der Rechtsfolge angepasst, sondern durch die Rechtsfolgenlösung contra legem die Rechtsfolge dem Tatbestand ${ }^{211}$. Die Anwendung von $\S 49$ Abs. 1 StGB auf $\S 211$ StGB hat freilich die systematisch kaum tragbare Konsequenz, dass an die Stelle von lebenslanger Freiheitsstrafe eine Freiheitsstrafe nicht unter drei Jahren treten würde - also zwei Jahre weniger als die Mindeststrafe bei $\S 212$ Abs. 1 StGB! Die Rechtsprechung passt daher zusätzlich noch einmal die Strafrahmenänderung des $\S 49$ Abs. 1 StGB an die Bedürfnisse der von ihr selbst ins Leben gerufenen Rechtsfolgenlösung $a^{212}$. Neben diesen Restriktionsversuch treten weitere Ansätze einer Begrenzung der Anwendbarkeit des § 211 StGB. Die Normativierung des Arglosigkeitsmerkmals im Falle einer durch das Opfer ausgelösten Notwehrlage ${ }^{213}$ ist in weiteren Entscheidungen nicht aufgegriffen worden. Ein weiteres Ventil, dem Diktat der absolut angedrohten lebenslangen Freiheitsstrafe zu entkommen, ist die Erhöhung der Anforderungen an das Ausnutzungsbewusstsein ${ }^{214}$. Diesbezüglich hat Rengier nachweisen können, dass die Rechtsprechung diese Voraussetzung in einer unberechenbaren Art und Weise handhabt ${ }^{215}$. Schließlich wird in der Literatur auf die Strategie einer großzügigen Zuerkennung verminderter Schuldfähigkeit gemäß § 21 StGB aufmerksam gemacht ${ }^{216}$.

Es ist daher zu begrüßen, dass sich die Expertengruppe mit großer Mehrheit dafür ausgesprochen hat, von der Exklusivität der lebenslangen Freiheitsstrafe abzurücken. Die Verwirklichung eines Abgrenzungsmerkmals auf Tatbestandsebene, das die Tötung als höchststrafwürdig definiert, soll nicht weiterhin zwingend mit lebenslanger Freiheitsstrafe bedroht werden ${ }^{217}$. Abgelehnt wurde jedoch der Vorschlag, das Exklusivitäts-Absolutheits-Verhältnis durch eine neben der lebenslangen Freiheitsstrafe angedrohte zeitige Freiheitsstrafe aufzulösen ${ }^{218}$.

210 Entsprechende Diagnose bezüglich der Verdeckungsabsicht bei Heine, GA 2000, 301, $311 \mathrm{f}$.

211 Siehe BGHSt. 42, 301, 304; vgl. Deckers/Fischer/König/Bernsmann, NStZ 2014, 9, 10: praktisch Vereinzelung der Rechtsfolgenlösung.

212 Zu den Verwerfungen durch die Rechtsfolgenlösung Günther, NJW 1982, $353 \mathrm{ff}$.

213 BGHSt. 48, $207 \mathrm{ff}$.

214 Vgl. schon BVerfGE 45, $187 \mathrm{ff}$.

215 Rengier, Festschrift für Küper, 2007, S. 473, 484; ebenso die Diagnose von Deckers, in: Abschlussbericht (Anm. 4), S. 443, $448 \mathrm{ff}$.

216 AE-Leben, GA 2008, 193, 203; Deckers/Fischer/König/Bernsmann, NStZ 2014, 9, 16.

217 Beratungsergebnisse, in: Abschlussbericht (Anm. 4), S. 55.

218 Beratungsergebnisse, in: Abschlussbericht (Anm. 4), S. 57. 
Nicht durchsetzen konnte sich auch die Option, eine Strafzumessungsregel für minder schwere Fälle des Mordes $\mathrm{zu}$ schaffen $^{219}$. Jeweils wurde die dadurch erzeugte Konturlosigkeit als Gegenargument angeführt ${ }^{220}$. Angenommen wurde hingegen mit relativer Mehrheit der Vorschlag, das Exklusivitäts-AbsolutheitsVerhältnis durch eine Privilegierung für Fälle erheblich herabgesetzten Unrechts bzw. erheblich herabgesetzter Schuld aufzulösen ${ }^{221}$. Zuzugeben ist, dass eine bloß fakultative Androhung lebenslanger Freiheitsstrafe $\mathrm{zu}$ einer erheblichen Unbestimmtheit auf der Rechtsfolgenseite führt. Zu bezweifeln ist gleichwohl, dass die Erfassung sämtlicher unrechts- bzw. schuldmindernder Momente durch die Einführung einer Privilegierung, die offenbar bezüglich des Mordes eine Sperrwirkung ausüben würde, die bessere Alternative wäre. Sicherlich ist es möglich, Unrechtsminderungen zu vertypen und als tatbestandliche Anknüpfungspunkte für eine Privilegierung auszugestalten. Die Haustyrannenfälle könnten daher, sofern entsprechende unrechtsmindernde Umstände vorhanden sind, berücksichtigt werden. Fraglich ist jedoch, ob man die Fülle lediglich schuldmindernder Dispositionen gerade auch in ihrem Ausmaß abschließend und hinreichend konkret umschreiben kann, ohne eine Generalklausel zu implementieren, die nicht bestimmter wäre als ein Mordtatbestand mit lediglich fakultativ angedrohter lebenslanger Freiheitsstrafe.

Für die bloß fakultative Androhung der lebenslangen Freiheitsstrafe und gegen die Aussonderung von Fällen mit lediglich schuldmindernden Umständen aus dem Mordtatbestand und ihre Verlagerung auf eine Privilegierung spricht zudem, dass es grundsätzlich Aufgabe der Tatbestände ist, Unrecht zu vertypen. Die Zubilligung eines Strafrahmens ist das normale gesetzgeberische Mittel, um Schulddivergenzen bei der Festlegung der Sanktion Rechnung tragen zu können. Es wäre wertungswidersprüchlich, unter den Voraussetzungen des $§ 21$ StGB dem Täter das Stigma des $§ 211$ StGB nicht zu ersparen, in Fällen von Verzweiflung jedoch auf eine Privilegierung auszuweichen. Nun könnte man erwägen, § 21 StGB leerlaufen zu lassen und alle Fälle mit erheblichen Schuldminderungen nur mit Hilfe der Privilegierung zu regeln. Dieses Vorgehen würde zwar innerhalb der $\S \S 211 \mathrm{f}$. StGB die Wertungswiderspruchsfreiheit gewährleisten, nicht aber im Verhältnis zu anderen Tatbeständen des Besonderen Teil des Strafgesetzbuchs.

Schließlich ist ein zentraler handwerklicher Fehler zu monieren: Es wurde mit absoluter Mehrheit der Stimmen der Beschluss gefasst, dass eine § 213 StGB entsprechende Regelung (als Nachfolgetatbestand des geltenden § 213 StGB) nur

219 Beratungsergebnisse, in: Abschlussbericht (Anm. 4), S. 57.

220 Beratungsergebnisse, in: Abschlussbericht (Anm. 4), S. $55 \mathrm{ff}$.

221 Beratungsergebnisse, in: Abschlussbericht (Anm. 4), S. 58. 
auf den Grundtatbestand, nicht aber auf die höchststrafwürdige Tötung Anwendung finden soll ${ }^{222}$. Dieser Beschluss ist offenbar so zu verstehen, dass der Nachfolgetatbestand des geltenden $\S 213$ StGB im Verhältnis zu $\S 211$ StGB keine Sperrwirkung haben soll ${ }^{223}$. Daraus wäre wiederum zu schließen, dass es sich bei der Privilegierung nicht um die Neufassung des § 213 StGB handeln würde, sondern nur um einen eigenen Tatbestand. Aber wie soll sich diese Privilegierung zwischen den Grundtatbestand des $\S 212$ StGB mit lebenslanger Freiheitsstrafe bei besonders schweren Fällen und die Qualifikation des § 211 StGB schieben können? Die Vorschläge der Expertengruppe sprengen an dieser Stelle jede nachvollziehbare Systematik.

\section{c) Die Aussetzung des Strafrestes zur Bewährung bei lebenslanger Freiheitsstrafe}

\section{aa) Die Unstimmigkeit der Beschränkung der Strafvollstreckung}

Nach $\S 57$ a StGB kann das Gericht bekanntlich die Vollstreckung des Restes einer lebenslangen Freiheitsstrafe nach fünfzehn Jahren Strafverbüßung zur Bewährung aussetzen, wenn nicht die besondere Schwere der Schuld des Verurteilten die weitere Vollstreckung gebietet, wenn die Aussetzung des Restes unter Berücksichtigung der Sicherheitsinteressen der Allgemeinheit verantwortet werden kann und wenn die verurteilte Person einwilligt. §57b StGB ordnet an, dass bei der Beurteilung der besonderen Schwere der Schuld die einzelnen Straftaten zusammenfassend zu würdigen sind, wenn auf lebenslange Freiheitsstrafe als Gesamtstrafe erkannt worden ist. Die $\S \S 57$ a, 57b StGB verfolgen denselben Regelungszweck wie $\S 57$ StGB, der die Strafaussetzung zur Bewährung bei zeitiger Freiheitsstrafe regelt: die Wiedereingliederung des Verurteilten in die Gesellschaft ${ }^{224}$. Es ist jedoch schwer begreiflich, warum bei einem zu lebenslanger Freiheitsstrafe verurteilten Straftäter schon nach fünfzehn Jahren derartige Resozialisierungsbemühungen unternommen werden sollen. Genau genommen besteht bei einer lebenslangen Freiheitsstrafe überhaupt kein Resozialisierungsbedarf. Der vom Bundesverfassungsgericht verfassungsrechtlich in Art. 2 Abs. 1 GG i.V.m. Art. 1 Abs. 1 GG verankerte Resozialisierungsanspruch ${ }^{225}$, der primär vollzugsrechtliche Konsequenzen zur Folge hat, und das Institut der lebenslangen

222 Beratungsergebnisse, in: Abschlussbericht (Anm. 4), S. 63.

223 Kritisch Momsen, StV 2015, Heft 12, Editorial, S. I.

224 BVerfG StV 2015, 242ff.; Groß, in: MK (Anm. 186), § 57 a Rdn. 1, 3; Kett-Straub (Anm. 105), S. 96: positive Spezialprävention.

225 BVerfGE 33, 1, 10 f.; 35, 202, 235f.; 45, 187, 238f.; 64, 261, 277; 98, 169, 201; 117, 71, 112. 
Freiheitsstrafe stehen - moderat formuliert - in einem Spannungsverhältnis. Widersprüchlich ist zudem die Annahme des $\S 57$ a StGB, dass nur bei besonderer Schwere der Schuld die weitere Vollstreckung geboten ist. Die Verhängung lebenslanger Freiheitsstrafe dient gerade dem Schuldausgleich. Ihr Vollzug ist daher aus diesem Grund zur Erreichung des Strafzwecks grundsätzlich auch erforderlich - ungeachtet des Umstandes, dass das ökonomische Gesetz des abnehmenden Grenznutzens auch in diesem Kontext Gültigkeit besitzt. Warum nur bei besonderer Schwere der Schuld - ungeachtet der Sicherungsinteressen der Allgemeinheit und der fehlenden Zustimmung des Verurteilten - die Freiheitstrafe nach fünfzehn Jahren Strafverbüßung weiter vollstreckt werden muss, ist rational nicht zu erklären. Die „Grundschuld“ bei einem Mord bietet bei unbefangener Betrachtungsweise eine hinreichende Legitimation für die Vollstreckung der lebenslangen Freiheitsstrafe, wenn dies auch für ihre Verhängung gilt.

Nun verdankt sich die Einführung der §§ 57a, 57b StGB bekanntlich der Entscheidung des Bundesverfassungsgerichts zur lebenslangen Freiheitsstrafe, die die damals gängige Begnadigungspraxis als rechtsstaatswidrig angeprangert hatte $^{226}$. Nach Auffassung des Bundesverfassungsgerichts wäre es mit der Menschenwürde gemäß Art. 1 Abs. 1 GG und dem Sozial- und Rechtsstaatsprinzip gemäß Art. 20 Abs. 3 GG unvereinbar, wenn der Staat den Menschen seiner Freiheit entkleiden würde, ohne dass zumindest die Chance besteht, je wieder der Freiheit teilhaftig werden zu können. Ein menschenwürdiger Vollzug (!) der lebenslangen Freiheitsstrafe sei nur dann sichergestellt, wenn der Verurteilte eine konkrete und grundsätzlich auch realisierbare Chance habe, zu einem späteren Zeitpunkt seine Freiheit wiedergewinnen zu können. Die Androhung einer lebenslangen Freiheitsstrafe soll daher der Ergänzung durch einen sinnvollen Behandlungsvollzug bedürfen. Dieser müsse auf die Resozialisierung der Gefangenen hinwirken und deformierenden Persönlichkeitsveränderungen entgegenwirken. Allerdings meint das Bundesverfassungsgericht, dass die Menschenwürde dann nicht verletzt werde, wenn der Vollzug der Strafe wegen der fortdauernden Gefährlichkeit der Gefangenen notwendig sei. Und wohl aus diesem Grund hat das Bundesverfassungsgericht die konkrete Chance der zukünftigen Freilassung unter Vorbehalt gestellt: Der Kern der Menschenwürde soll erst dann betroffen sein, wenn der Verurteilte ungeachtet seiner Persönlichkeitsentwicklung jegliche Hoffnung, seine Freiheit wiederzulangen, aufgeben müsse ${ }^{227}$.

Das Bundesverfassungsgericht hat seine grundlegende Entscheidung in einem späteren Beschluss noch einmal bestätigt: Die unter Umständen lebenslange 
Vollstreckung der Freiheitsstrafe bei fortbestehender Gefährlichkeit des Täters über die besondere Schwere der Schuld hinaus verletze nicht die Menschenwürde (Art. 1 Abs. 1 GG) oder das Freiheitsgrundrecht (Art. 2 Abs. 2 GG). Insbesondere werde damit keine schuldunabhängige, vom Erfordernis der Schuldangemessenheit der Strafe nicht mehr gedeckte Strafvollstreckung zugelassen ${ }^{228}$. Das Bundesverfassungsgericht hat des Weiteren entschieden, dass es von Verfassungs wegen nicht grundsätzlich ausgeschlossen sei, eine lebenslange Freiheitsstrafe ein Leben lang zu vollstrecken. Dies gelte insbesondere dann, wenn die Schwere der Schuld die Vollstreckung der Strafe über ihre Mindestverbüßungsdauer hinaus geböte und der Verurteilte sich inzwischen im vorgerückten Alter befinde. Allerdings hat das Bundesverfassungsgericht eingeschränkt, dass bei einer weit über fünfzehn Jahren hinausreichenden Verbüßungsdauer es gegen die Menschenwürde verstoßen würde, eine Entlassung erst dann in Betracht zu ziehen, wenn körperliche oder geistige Gebrechen eingetreten oder der Tod nahe sei ${ }^{229}$.

Diese Argumentation ist jedoch inkonsistent: Besteht der Eingriff in die Menschenwürde in dem lebenslangen Vollzug als solchem allein aufgrund der Auswirkung des Vollzugs auf den Inhaftierten bzw. in der Aussicht als solcher auf einen lebenslangen Vollzug, dann kann es für den Verstoß gegen die Menschenwürde nicht darauf ankommen, ob der Inhaftierte eine Gefahr für die Gesellschaft darstellt, weil er anders als andere Gefangene über keine positiv veränderbare Persönlichkeit verfügt, oder ob ihm eine besondere Schwere der Schuld zur Last fällt. Der Standpunkt des Bundesverfassungsgerichts würde auf eine Relativierung der Menschenwürde hinauslaufen ${ }^{230}$. Zur Vermeidung dieser Konsequenzen hätte das Bundesverfassungsgericht schon jeweils die Verhängung der lebenslangen Freiheitsstrafe ablehnen müssen. Dass andere Gefangene eine Entlassungsoption besitzen, kann den lebenslang Inhaftierten nicht belasten und daher den Verstoß gegen seine Würde nicht ausschließen. Indem das Bundesverfassungsgericht die Gefährdung der Allgemeinheit durch den Inhaftierten oder die besondere Schwere der Schuld in den Blick nimmt, rekurriert es in Wahrheit auf die materiellen Gründe für den Freiheitsentzug und verlässt damit die reine Vollzugsebene. Entscheidend wäre also, ob der Staat einen akzeptablen Grund hat, einen Bürger trotz der Depersonalisierungsrisiken lebenslang $\mathrm{zu}$ inhaftieren. Stellt man die Judikatur des Bundesverfassungsgerichts auf rationale Füße, muss mithin schon auf der Anordnungsebene bei Bemessung der Länge der Freiheits-

228 BVerfGE 117, 71ff.

229 BVerfGE 72, $105 \mathrm{ff}$.

230 Davon ist die Frage zu trennen, ob die Feststellung einer Menschenwürdeverletzung unter Umständen eine Abwägung voraussetzt; siehe dazu Herdegen, in: Maunz/Dürig, 75. Lfg. (September 2015), Art. 1 Rdn. $74 \mathrm{ff}$. 
strafe berücksichtigt werden, wie sich der Vollzug auf den Verurteilten auswirken wird. Diese Auswirkungen sind dem Staat zuzurechnen, so dass sie bei der Bestimmung der Eingriffsschwere einkalkuliert werden müssen. Geschieht dies nicht, verstößt der Staat durch die Verhängung lebenslanger Freiheitsstrafe gegebenenfalls gegen das Schuldprinzip und damit gegen die betroffenen Grundrechte des Verurteilten. Und umgekehrt: Verstößt die Auferlegung lebenslanger Freiheitsstrafe nicht gegen den Verhältnismäßigkeitsgrundsatz, darf von Verfassungs wegen die Freiheitsstrafe vollständig vollzogen werden.

Diese Neujustierung hätte allerdings die Konsequenz, dass in den Fällen, in denen es an der besonderen Schwere der Schuld fehlt, schon keine lebenslange Freiheitsstrafe hätte angeordnet werden dürfen. Nun könnte man erwidern, dass die vollzugsrechtliche Einordnung der Problematik seitens des Bundesverfassungsgerichts den Vorteil bieten würde, die Schutzinteressen der Gesellschaft berücksichtigen zu können, da die Aussetzung des Strafrestes nur möglich ist, wenn dies unter Berücksichtigung der Sicherheitsinteressen der Allgemeinheit verantwortbar ist. Die Anerkennung dieses Arguments würde jedoch bedeuten, der lebenslangen Freiheitsstrafe eben doch - ganz im Sinne der oben wiedergegebenen Diagnose von Arzt - eine versteckte Maßregelfunktion aufzuerlegen ${ }^{231}$. Da indes diese Vermengung von Strafe und Maßregel abzulehnen ist, ist der Rüge zuzustimmen, die lebenslange Freiheitsstrafe werde gleichzeitig abgeschafft und beibehalten und ein inkonsistentes Regelsystem etabliert ${ }^{232}$. Sollte man zu der (hier nicht geteilten) Einschätzung gelangen, dass die Anordnung der zeitigen Freiheitsstrafe nicht den Sicherheitsbedürfnissen der Allgemeinheit genüge, müsste durch Gesetz die Möglichkeit geschaffen werden, unter Beachtung verfassungsrechtlicher Vorgaben zusätzlich Sicherungsverwahrung anzuordnen.

So unstimmig die Verortung der verfassungsrechtlichen Restriktionen durch das Bundesverfassungsgericht auf Vollzugsebene in dogmatischer Hinsicht ist, so nachvollziehbar ist sie allerdings in rechtspolitischer Hinsicht, da sie vordergründig das Institut der lebenslangen Freiheitsstrafe unangetastet gelassen hat und daher nicht auf Akzeptanzvorbehalte gestoßen ist. Es wäre aber jetzt nach über vier Jahrzehnten an der Zeit, den „Etikettenschwindel“ zu beenden und zumindest einen weiteren Schritt der Zurückdrängung der lebenslangen Freiheitsstrafe zu wagen, in dem die Begrenzung von der Vollzugs- auf die Anordnungsebene transferiert wird. Es ist daran zu erinnern, dass es das Bundesverfassungsgericht selbst gewesen ist, das auf den noch zurückzulegenden Weg in

231 Vgl. die Einschätzung von Heine, GA 2000, 301, 313, dass an der Auffassung des Fortbestehens einer Sicherheitsstrafe schwer vorbeizukommen sei.

232 Kargl, StraFo 2001, 365. 
seiner ersten Entscheidung aufmerksam gemacht hat ${ }^{233}$. Dennoch hat die Expertengruppe, ohne sich mit den hier geäußerten Bedenken und Einwänden auseinanderzusetzen, für die Beibehaltung der Schuldschwereklausel des $\S 57 \mathrm{a}$ StGB gestimmt ${ }^{234}$, obwohl diese genau genommen eine versteckte materiellrechtliche Bedeutung hat ${ }^{235}$. Die Möglichkeit, die Begrenzung der Inhaftierung von der Vollstreckungs- auf die Verhängungsebene zu transferieren, hat sich die Expertengruppe schon durch die Ablehnung einer bloß fakultativen Androhung der lebenslangen Freiheitsstrafe verbaut.

\section{bb) Die Feststellung besonderer Schwere der Schuld}

Offensichtlich bereitet es der Rechtsprechung zudem große Schwierigkeiten, eine rationale, kalkulierbare und vor allem einheitliche Handhabung der Schuldschwereklausel des $\S 57$ a Abs. 1 Nr. 2 StGB zu gewährleisten. An dieser Einschätzung vermag auch der Beschluss des Bundesverfassungsgerichts aus dem Jahre 1992 nichts zu ändern, in dem es dem Tatbestandsmerkmal der besonderen Schwere der Schuld hinreichende Bestimmtheit attestiert, zugleich aber verlangt hat, dass die Entscheidung über seine Verwirklichung vom Schwurgericht zu fällen und das Vollstreckungsgericht daran gebunden sei $^{236}$. Der Begriff der besonderen Schwere der Schuld setzt einen Vergleich voraus. Darüber, welche Vergleichsgröße heranzuziehen ist, herrschte Streit. Ein Teil der höchstrichterlichen Judikatur hatte die Abweichung des gesamten Tatbildes einschließlich der Täterpersönlichkeit von den erfahrungsgemäß vorkommenden Mordfällen für maßgeblich gehalten ${ }^{237}$. Die Gegenauffassung hatte es unter Verweis auf die Judikatur des Bundesverfassungsgerichts $^{238}$, die allerdings später eine Änderung erfuhr ${ }^{239}$, für erforderlich gehalten, dass das für die lebenslange Freiheitsstrafe vorausgesetzte Mindestmaß an Schuld in besonderem Maße überschritten sein müsse ${ }^{240}$. Überspitzt formuliert hängt von dieser Festlegung ab, ob die Mindestverbüßungszeit eher die Regel oder die Ausnahme ist ${ }^{241}$. Der Große Senat hat sich in seiner Entscheidung keiner dieser Positionen angeschlossen. Es handle sich nicht um eine Strafzumessungs-, sondern um

233 BVerfGE 45, 187, 229.

234 Beratungsergebnisse, in: Abschlussbericht (Anm. 4), S. 64.

235 So auch Heine, GA 2000, 301, 311.

236 BVerfGE 86, $288 \mathrm{ff}$.

237 BGH NStZ 1993, 235; NJW 1993, 1999, 2000.

238 BVerfGE 64, 261, 271.

239 BVerfGE 86, 288, 314; BVerfG NStZ 1993, 431.

240 BGH NStZ 1994, 77, 78; NStZ 1994, 540 f.

241 So Kett-Straub (Anm. 105), S. 225. 
eine Vollstreckungsentscheidung. Die übliche Mordtat lasse sich ebenso wenig bestimmen wie die Mordtat mit Mindestschuldgehalt. Ein erhöhtes Maß an Berechenbarkeit und gleichmäßiger Rechtsanwendung sei daher mit beiden Standpunkten nicht gewonnen. Der Tatrichter habe demnach ohne Bindung an begriffliche Vorgaben die schuldrelevanten Gesichtspunkt $\mathrm{zu}$ ermitteln und $\mathrm{zu}$ gewichten. Die Feststellung der besonderen Schwere der Schuld könne dabei nur in Betracht kommen, wenn Umstände von Gewicht vorlägen ${ }^{242}$.

Die mit dieser Entscheidung einhergehende Preisgabe einer an sich logisch geforderten Referenzgröße birgt die Gefahr einer Divergenz der Beurteilung der Schuldschwere durch die Tatgerichte ${ }^{243}$. Die Sorge wird zusätzlich noch dadurch verstärkt, dass sich die Prüfung der Revisionsgerichte darauf beschränkt, ob der Tatrichter alle maßgeblichen Umstände bedacht und rechtsfehlerfrei abgewogen hat, und die Revisionsgerichte sich daran gehindert sehen, ihre eigene Wertung an die Stelle derjenigen des Tatrichters zu setzen ${ }^{244}$. Es ist allerdings zu bemerken, dass der zweite Senat in mehreren Entscheidungen wiederum auf die Abweichung von den erfahrungsgemäß vorkommenden Fällen des Mordes abstellt ${ }^{245}$. Die Expertengruppe ist auf dieses zentrale Anwendungsproblem des $\S 57$ a Abs. 1 Nr. 2 StGB mit keinem Wort eingegangen.

Es bestehen zudem Zweifel, ob die Differenzierungen der Judikatur wirklich stets tragfähig sind. Die Feststellung der besonderen Schwere der Schuld soll einer einzelfallabhängigen Gesamtwürdigung von Tat und Täterpersönlichkeit bedürfen ${ }^{246}$. Nachvollziehbar ist es, wenn die Rechtsprechung die Ermordung mehrerer Opfer durch die Tat ${ }^{247}$ oder die tatmehrheitliche Begehung von Mordtaten berücksichtigt ${ }^{248}$. Dasselbe gilt unter Umständen für die Berücksichtigung der Begehung weiterer (schwerer) Straftaten ${ }^{249}$. Nicht plausibel ist es jedoch,

242 BGHSt. (GS) 40, 360, $366 \mathrm{ff}$.

243 Kritisch auch Krümpelmann, NStZ 1995, 329; Heine, GA 2000, 309 f.; Kett-Straub (Anm. 105), S. $224 \mathrm{f}$.

244 BGHSt. (GS) 40, S. 360, 370; 41, 57, 62; 42, 226, 227; BGH NStZ-RR 1996, 354; NStZ 1998, 352, 353; NStZ-RR 2001, 296; StV 2001, 571; StraFo 2001, 390; NStZ 2002, 49; StV 2003, 18, 19; NStZ 2003, 146; NStZ-RR 2004, 164; NStZ 2006, 505; NStZ-RR 2006, 236, 237; NStZ 2009, 204; 2009, 260; NStZ-RR 2012, 339; NStZ 2014, 212; 2014, 511.

245 BGH NStZ 2009, 260; NStZ-RR 2012, 339; NStZ 2014, 212.

246 BGHSt. (GS) 40, 360, 370; BGH StV 2003, 18, 19; StraFo 2001, 390; NStZ-RR 2002, 137; NStZ 2002, 49; 2003, 146, 148; StV 2005, 329; NStZ 2006, 236, 237; 2006, 505, 506; 2009, 204; NStZ-RR 2012, 339; 2014, 164.

247 BGH NJW 1993, 1999, 2000; NStZ 1994, 540, 541; 2003, 146, 148.

248 BGHSt. (GS) 40, 360, 370; BGH NStZ 1994, 540, 541; NStZ 2002, 49, 50.

249 BGHSt. (GS) 40, 360, 370; NStZ 1994, 540, 541; 1999, 501, 502; NStZ-RR 2002, 137; NStZ 2002, 49,50 . 
wenn die Rechtsprechung als Indiz für die besondere Schwere der Schuld die Verwirklichung mehrerer Mordmerkmale heranzieht ${ }^{250}$. An dieser Stelle kommen wieder die Bedenken vor allem gegen die Mordmerkmale der ersten und dritten Gruppe zum Tragen. So ist die besondere Verwerflichkeit der Motive ${ }^{251}$ - wie aus den obigen Darlegungen deutlich geworden sein sollte - von vornherein ein völlig unerheblicher Gesichtspunkt. Die neuere Rechtsprechung macht nunmehr geltend, dass die besondere Verwerflichkeit schon Voraussetzung für das Vorliegen niedriger Beweggründe sei und wendet $\S 46$ Abs. 2 StGB entsprechend $\mathrm{an}^{252}$. Auch bestehen ernsthafte Zweifel, ob die besondere Verwerflichkeit der Tatausführung ${ }^{253}$ stets ein derartiges Indiz ist. In der Literatur wird die Auffassung vertreten, dass bei einem grausamen Vorgehen stets ein Fall mit besonderer Schuldschwere vorliege ${ }^{254}$. Für die besondere Schwere der Schuld sollen massive Vorstrafen, ein Bewährungsbruch und unter Umständen das Nachtatverhalten sprechen $^{255}$. Gegen diese auf der Hemmschwellentheorie beruhende Annahme sind ebenfalls hier leider aus Platzgründen nicht weiter ausführbare Bedenken anzumelden $^{256}$.

Insgesamt kann festgehalten werden, dass die Gefahr einer teilweise willkürlichen, kaum vorhersehbaren Handhabung des $§ 57$ a Abs. 1 Nr. 2 StGB nicht von der Hand zu weisen ist. Die Expertengruppe hat jeweils mit relativer Mehrheit beschlossen, die Faktoren, die die besondere Schwere der Schuld begründen können, ausdrücklich in das Gesetz aufzunehmen bzw. die Faktoren in Form einer exemplarischen Aufzählung zu normieren ${ }^{257}$. Ob schon damit dieser Gefahr effektiv begegnet werden kann, darf bezweifelt werden.

\section{Das Verhältnis von $\S 211$ StGB und $\S 212$ StGB}

Unklarheit herrscht schließlich über das Verhältnis von Mord und Totschlag. Die Rechtsprechung hält bekanntlich bis heute daran fest, dass es sich beim Mord um einen selbständigen Tatbestand und nicht um eine Qualifikation des § 212 StGB

250 BGH NJW 1993, 1999; NStZ 2003, 146, 148; 2006, 236, 237; 2014, 212; 2009, 204, unter der Voraussetzung, dass das weitere Mordmerkmal schulderhöhende Umstände aufzeigt.

251 BGHSt. (GS) 40, S. 360, 370; BGH NStZ 1994, 540, 541.

252 BGHSt. 41, 226, 228; BGH NStZ 1997, 123.

253 BGHSt. (GS) 40, 360, 370; BGH NJW 1993, 1999, 2000; NStZ 1994, 540, 541; 2002, 49, 50; 2003, 146, 148; 2006, 236, 237.

254 Kett-Straub (Anm. 105), S. $261 \mathrm{ff}$.

255 BGH NStZ 2005, 88; 2014, 511, 512.

256 Ähnliche Einschätzung bei Kinzig, in: Abschlussbericht (Anm. 4), S. 529, 578 ff.

257 Beratungsergebnisse, in: Abschlussbericht (Anm. 4), S. $64 \mathrm{f}$. 
handeln soll ${ }^{258}$. Sie kann sich dabei in systematischer Hinsicht auf die Anordnung der $\S \S 211,212$ StGB und den Wortlaut des § 212 StGB („ohne Mörder zu sein“) berufen. Die Tätertypenlehre als strafrechtsideologische Basis für diese Rechtsansicht ist aber - darauf wurde oben schon aufmerksam gemacht - nach dem Zweiten Weltkrieg weggebrochen. Auf die wenig überzeugenden Konsequenzen der Rechtsprechungsansicht für die Teilnahme am Mord im Hinblick auf die Regelung der besonderen persönlichen Merkmale in $\S 28$ StGB sei hier nur kurz hingewiesen ${ }^{259}$. Durch die Ausgestaltung des Mordes als Qualifikation des Totschlags beseitigt die Expertengruppe zumindest eine Baustelle der Tötungsdelik$\mathrm{te}^{260}$. Es bedarf keiner näheren Ausführungen, dass diese Änderung zu begrüßen wäre, falls man nicht dem Privilegierungsmodell folgen würde.

\section{Die Ausgestaltung des $\S 213$ StGB}

Die Expertengruppe hat - wie oben schon angedeutet - für die Beibehaltung des $\S 213$ StGB plädiert, zugleich aber Änderungsbedarf angemahnt ${ }^{261}$. Entschieden wurde ferner, dass eine $\S 213$ StGB entsprechende Regelung die minder schweren Fälle abschließend - also unter Ausschluss eines unbenannten minder schweren Falles - regeln solle. Angenommen wurde der Vorschlag, die Provokation durch die Formulierung „wurde der Täter ohne eigene Schuld durch eine ihm, einem Angehörigen oder einer anderen ihm nahestehenden Person zugefügte Misshandlung oder schwere Beleidigung zum Zorn gereizt oder in eine vergleichbar heftige Gemütsbewegung versetzt und hierdurch auf der Stelle zur Tat hingerissen“ zu erfassen. Des Weiteren wurde beschlossen, die Verzweiflung des Täters strafmildernd zu berücksichtigen und durch die Formulierung „handelt der Täter, um sich oder einen Angehörigen oder eine ihm nahestehende Person aus einer unverschuldeten oder ihm ausweglos erscheinenden Konfliktlage [und allgemein begreiflichen] Zwangs-/Konfliktlage zu befreien“ in den Katalog des § 213 StGB aufzunehmen. Angenommen wurde schließlich der Vorschlag, die Mindestdauer der anzudrohenden Freiheitsstrafe auf zwei Jahre anzuheben. Alle Beschlüsse wurden mit absoluter Mehrheit gefasst ${ }^{262}$.

Ob dieser Regelungsvorschlag der gegenwärtig geltenden Fassung des § 213 StGB vorzuziehen ist, muss hinsichtlich des Konfliktmodells, auf dem die Ver-

258 BGHSt. 1, 368, 370; 6, 329, 330; 22, 375, 377; 50, 1, 5.

259 Vgl. Deckers/Fischer/König/Bernsmann, NStZ 2014, 9, 10.

260 Beratungsergebnisse, in: Abschlussbericht (Anm. 4), S. $24 \mathrm{ff}$.

261 Beratungsergebnisse, in: Abschlussbericht (Anm. 4), S. 62.

262 Beratungsergebnisse, in: Abschlussbericht (Anm. 4), S. $62 \mathrm{f}$. 
zweiflungsvariante beruht, in Frage gestellt werden. Es fehlt jegliche Begründung dafür, warum die Verzweiflung auf einer Konfliktlage beruhen und menschlich begreiflich sein muss, um strafmildernd zu wirken. Das Konfliktmodell stammt von Eser. Seiner Ansicht nach ist die Privilegierung der Tötung im Affekt nicht nur ein psychologisches, sondern hauptsächlich ein normatives Problem, obgleich er die schuldmindernde Relevanz des Affekts zugesteht. Aus generalpräventiven Gründen soll jedoch seine sozialethische Tolerierung kraft der Strafmilderung nur dann akzeptabel sein, wenn der Affekt durch einen längerfristigen interpersonalen Konflikt verursacht wurde und daher seine Wurzeln mehr in der dem Täter nicht beherrschbaren singulären Situation und weniger in seiner charakterlichen Fehldisposition bzw. in seiner negativen Einstellung gegenüber dem Rechtsgut Leben liegen, für die der Täter selbst die Verantwortung trägt. Begreiflich soll demgemäß der Affekt dann sein, wenn unter gleichen Umständen auch ein rechtsloyaler Charakter bzw. ein Täter mit rechtsloyaler Gesinnung in eine vergleichbare heftige Gemütsbewegung geraten wäre. Nur eine Dekulpierung unter diesen engen Voraussetzungen vermeidet nach Auffassung von Eser, dass die Privilegierung des Affekts als Nachgiebigkeit gegenüber mangelnder Gefühlsbeherrschung verstanden wird und langfristig zum Abbau von Tötungshemmungen beiträgt ${ }^{263}$. Kritik ist an der Bevorzugung sozialethischer statt rechtlicher Kriterien zu üben. Diese lässt besorgen, dass die rechtliche Bewertung der Tat auf alltagsmoralische Evidenzen gestützt wird ${ }^{264}$, wenngleich der für erforderlich gehaltenen Prüfung, ob der Täter bei einer rechtsloyalen Gesinnung in eine vergleichbare heftige Gemütsbewegung geraten wäre, möglicherweise ein rationaler Kern innewohnen mag. Zwar kann man sich nicht, wenn man das Schuldprinzip erst nimmt, auf generalpräventive Erwägungen stützen ${ }^{265}$. Sie erinnert jedoch an die Rechtsfigur der actio libera in causa. Beruht der Affekt auf einer Einstellung, die mit den Vorgaben unserer Rechtsordnung nicht übereinstimmt - wie zum Beispiel bei Gemütsbewegungen wie Hass, Wut oder Zorn, die in einer rassistischen Gesinnung wurzeln - darf sich der Täter auf die Schuldminderung nicht berufen. Allerdings stellt sich unter anderem das Problem, dass - wie oben dargestellt - die Rechtsgemeinschaft gegenüber dem Täter keinen Anspruch auf eine bestimmte Gesinnung hat.

Doch wie auch immer: Unklar bleibt, warum ein in diesem Sinne begreiflicher Affekt nur im Rahmen eines Konflikts beachtlich sein soll - zumal rechtliche Maßstäbe dafür fehlen, unter welchen Voraussetzungen der erforderliche Konflikt

263 Eser (Anm. 148), D 126 ff.; ihm folgend Beckmann, GA 1981, 337, 346 ff.; vgl. auch AE-Leben, GA 2008, 193, 199, 204f., 207, 248f.

264 So schon Grünewald (Anm. 33), S. 227; vgl. aber die zustimmende Einschätzung bei Müssig (Anm. 14), S. 342.

265 Siehe im Kontext der Affekttat Haas, Festschrift für Krey, 2010, S. 117, 133 ff. 
ein relevantes Ausmaß angenommen hat ${ }^{266}$. Nicht zu erklären ist zudem, warum es immer bei und nur bei einem ausweglos erscheinenden Konflikt nicht darauf ankommen soll, ob der Täter ihn verschuldet hat oder nicht. Des Weiteren ist zu monieren, dass bei einem Affekt, der die Schwelle des § 21 StGB überschreitet, eine Milderung der Strafe des $\S 212$ StGB gemäß $\S 49$ Abs. 1 StGB vorzunehmen ist, bei einem Affekt wie Verzweiflung, bei dem nicht die für $\S 21$ StGB geforderte Intensität erreicht wird, der minder schwere Fall des Totschlags eingreifen würde, dessen Strafuntergrenze identisch ist mit derjenigen, die aus der Anwendung von $\S 49$ StGB folgt, dessen Strafobergrenze aber sogar leicht niedriger ausfällt.

\section{Das Privilegierungsmodell als Alternative zur gegenwärtigen gesetzlichen Konzeption der Tötungsdelikte}

Aufgrund der dargelegten eklatanten Defizite der von der Expertengruppe ausgearbeiteten Gesetzgebungsempfehlungen soll zum Abschluss der Gesetzgebungsvorschlag vorgestellt werden, der von mehreren Mitgliedern der Expertengruppe unterbreitet wurde, aber in der Kommission keine Mehrheit gefunden hat $^{267}$. Dieser Gesetzgebungsvorschlag folgt den Vorgaben des im Grundsatz zu favorisierenden Privilegierungsmodells ${ }^{268}$. Das Privilegierungsmodell gestaltet den als vorsätzliche Tötung definierten Mord als Grundtatbestand aus, den Totschlag hingegen als Privilegierung. Der Reformentwurf verfolgt dabei das Ziel, das Rechtsgut „Leben“ aufzuwerten. Aus diesem Grund soll eine lebenslange Freiheitsstrafe schon dann verhängt werden können, wenn eine vorsätzliche Tötung vorliegt und keine täterbegünstigenden Umstände vorhanden sind. Alle Personen sollen dadurch denselben strafrechtlichen Schutz genießen. Auf die lebenslange Freiheitsstrafe soll wegen ihrer symbolischen Funktion nicht verzichtet werden. Die Rechtsfolge wird flexibler ausgestaltet, um die Umgehungs-

266 Vgl. die Kritik von Grünewald (Anm. 33), S. 228: „Konflikt“ als schillernder und konturenloser Begriff, der offen für alle denkbaren Inhalte sei.

$267 \S 211$ E Mord: Wer einen anderen Menschen tötet, wird mit lebenslanger Freiheitsstrafe oder mit Freiheitsstrafe nicht unter acht Jahren bestraft. § $212 \mathrm{E}$ Totschlag: Wurde dem Täter oder einer ihm nahestehenden Person ohne eigenes Zutun vom Getöteten eine schwere Beleidigung, Misshandlung oder andere Rechtsverletzung zugefügt und er hierdurch unmittelbar zur Tat veranlasst, so ist die Strafe Freiheitsstrafe von zwei bis zu zehn Jahren. § 213 wird gestrichen.

268 Für ein derartiges Modell auch Müssig (Anm. 14), S. 308 ff.; Grünewald (Anm. 33), S. 378 ff.; Sotelsek (Anm. 203), S. 393 ff.; Kubiciel, Festschrift für v. Heintschel-Heinegg, S. 267, 273 f.; Sympathien auch bei Momsen, StV 2015, Heft 12, Editorial, S. I. 
strategien der Rechtsprechung zur Vermeidung lebenslanger Freiheitsstrafe entbehrlich zu machen. Der Privilegierungstatbestand des Totschlags soll sich auf Fälle verringerten Tötungsunrechts beschränken. Die Verringerung des Tötungsunrechts wird damit begründet, dass der vorangegangene Eingriff des Opfers in die rechtlich geschützte Sphäre des Täters es erlaube, dem Opfer eine partielle Verantwortung für die Tat zuzuschreiben. Für wünschenswert halten es die Verfasser des Gesetzgebungsvorschlags, die Schuldschwereklausel des § 57a Abs. 1 Nr. 2 StGB ersatzlos zu streichen, da diese Vollstreckungsfragen mit Fragen der Strafbegründungsschuld vermenge. Die dadurch bewirkte Stufung der lebenslangen Freiheitsstrafe entspreche nicht dem Ziel des Regelungsentwurfs, das Rechtsgut „Leben“ als im höchsten Maße schützenswert zu betrachten. Bei einem Höchstmaß an Schuld bedürfe der Vollzug keiner weiteren Legitimation durch den Tatrichter. Die Aussetzung des Strafrestes zur Bewährung solle allein nach vollstreckungsrechtlichen Gesichtspunkten erfolgen ${ }^{269}$.

Der Reformentwurf ist hinsichtlich der inneren dogmatischen Stimmigkeit im Vergleich zur geltenden Rechtslage und zu den Empfehlungen der Mehrheit der Expertengruppe zweifellos ein Fortschritt. Sofern dem Privilegierungsmodell von Mitsch vorgeworfen wird, die Möglichkeit von Unrechtssteigerungen zu verkennen und aufgrund der Zweistufigkeit Unrechtsteigerungen und -minderungen nur asymmetrisch gewichten $\mathrm{zu}$ können ${ }^{270}$, ist an die oben dargelegte Einsicht $\mathrm{zu}$ erinnern, dass die unrechtsteigernden Umstände das Tötungsunrecht selbst nicht betreffen und daher grundsätzlich nur auf der Ebene der Konkurrenzen von Relevanz wären. Es ist zudem zu bedenken, dass nach Auffassung der Anhänger des Privilegierungsmodells die vorsätzliche Tötung als höchstes Unrecht ${ }^{271}$ schon hinreichend für die Auferlegung lebenslanger Freiheitsstrafe sein soll. Es bedarf also keiner Tatbestandsverschiebung zu Lasten des Täters mehr, wie es einer Tatbestandsverschiebung $\mathrm{zu}$ seinen Gunsten bedarf, wenn unrechtsmindernde Umstände vorhanden sind.

Ungeachtet dieser Verteidigung sind an dem Reformentwurf einige durchaus erhebliche Kritikpunkte anzubringen: Zunächst ist $\mathrm{zu}$ bemängeln, dass der eklatante Strafrahmensprung zwischen $\S 212$ Abs. 1 StGB und $\S 211$ StGB in den neu konzipierten $\S 211$ StGB transferiert werden würde. Dies gilt ungeachtet der Tatsache, dass die Mindeststrafe bei acht Jahren Freiheitsstrafe liegen soll und nicht wie gegenwärtig $\S 212$ StGB vorsieht - bei fünf Jahren. Entscheidend wäre die Diskrepanz zwischen der Höchstgrenze zeitiger Freiheitsstrafe von fünfzehn Jahren

269 Gesamtkonzeption von Deckers, Grünewald, König und Safferling, in: Abschlussbericht (Anm. 4), S. $90 \mathrm{ff}$.

270 Mitsch, JR 2015, 122, $125 \mathrm{f}$.

271 Grünewald, JA 2012, 401, 402; Sotelsek (Anm. 203), S. 274. 
gemäß $\S 38$ Abs. 2 StGB und lebenslanger Freiheitsstrafe. Unklar ist des Weiteren die Stoßrichtung der Kritik an der Schuldschwereklausel des $§ 57$ a Abs. 1 Nr. 2 StGB. Würde man die Klausel lediglich streichen, würde die vorzeitige Aussetzung des Strafrests zur Bewährung im Vergleich zur gegenwärtigen Rechtslage erheblich ausgeweitet und damit die abgelehnte Stufung der lebenslangen Freiheitsstrafe fast zum Regelfall. Dies widerspräche der Ansicht der Verfasser, dass bei einem Höchstmaß an Schuld stets lebenslange Freiheitsstrafe angemessen sei und ihr vollständiger Vollzug keiner weiteren materiell-rechtlichen Legitimation bedürfe. Es gäbe dann keinen Grund mehr, die Vollstreckung der Freiheitsstrafe mit Ausnahme der Fälle, in denen die Allgemeinheit vor dem Gefangenen weiter gesichert werden müsste, stets nach fünfzehn Jahren zur Bewährung auszusetzen. Es wäre daher allein konsequent, § 57 a StGB insgesamt aufzuheben, da auch nicht ersichtlich ist, welche ausschließlich vollstreckungsrechtlichen Gesichtspunkte die vorzeitige Aussetzung des Strafrests zur Bewährung tragen könnten. Dies aber würde - betrachtet man die tatsächliche Vollzugsdauer - zu einer erheblichen Anhebung des Sanktionsniveaus führen, die nicht mehr im Einklang mit den Vorgaben des Bundesverfassungsgerichts stünde.

Es wäre daher zu überlegen, im Falle des Mordes, also der vorsätzlichen Tötung ohne Unrechtsminderung, eine Freiheitsstrafe von zehn bis dreißig Jahren anzudrohen und dann auf Vollstreckungsebene - wie sonst auch bei zeitiger Freiheitsstrafe - $\S 57$ StGB anzuwenden. Würde man auf eine Freiheitsstrafe von gut zwanzig Jahren erkennen, würde wie nach gegenwärtiger Rechtslage nach fünfzehn Jahren die Vollstreckung des Strafrestes zur Bewährung ausgesetzt. Unrechtserhöhende Umstände wie zum Beispiel ein besonders grausames und qualvolles Vorgehen des Täters könnten durch Ausschöpfung des Strafrahmens bei Festsetzung der Sanktionshöhe zu Lasten des Täters gebührend angerechnet werden, ohne sich dem Vorwurf einer Asymmetrie auszusetzen. In einem zweiten Absatz könnte für Fälle der Mehrfachtötung - beispielsweise bei einem Terroranschlag - Freiheitsstrafe von dreißig Jahren bis zu lebenslanger Freiheitsstrafe verhängt werden ${ }^{272}$. Der Verzicht auf eine vollständige Vollstreckung der Freiheitsstrafe wäre in diesen Fällen eine rein ausnahmsweise Gnadenentscheidung. Das Privilegierungsmodell würde durch diese Regelung etwas modifiziert werden. Es sei jedoch noch einmal betont, dass auch bei einem grausamen oder qualvollen Vorgehen des Täters zur Vermeidung von eklatanten Wertungswidersprüchen zu den Regelungen der $\S \S 52,53 \mathrm{StGB}^{273}$ die allgemeine Neuregelung der Konkurrenzen eindeutig der vorzugswürdigere Weg wäre.

272 So wohl auch Kinzig, in: Abschlussbericht (Anm. 4), S. 529, 590.

273 Vgl. die zutreffende Analyse von Mitsch, JR 2015, 122, $123 \mathrm{ff}$. 
Wie ist die Entwurfsfassung des Privilegierungstatbestandes $\mathrm{zu}$ beurteilen? Zuzustimmen ist aus den oben genannten Gründen der Entscheidung, den neu zu konzipierenden Privilegierungstatbestand des Totschlags grundsätzlich auf Fälle geminderten Unrechts zu begrenzen, die von den Verfassern auf die Mitverantwortung des Opfers gestützt wird ${ }^{274}$. Durch die bloß fakultative Androhung der lebenslangen Freiheitsstrafe könnten angesichts einer Mindeststrafe von acht Jahren Freiheitsstrafe schuldmindernde Umstände jenseits des $§ 21$ StGB ausreichend bei der Strafzumessung berücksichtigt werden. Insoweit besteht Übereinstimmung mit der hier vertretenen Ansicht. Kritik ist jedoch an der Voraussetzung zu üben, dass der Privilegierungstatbestand auf Fälle beschränkt werden soll, in denen das Opfer durch einen vorangehenden rechtswidrigen Eingriff in die rechtlich geschützte Sphäre des Täters diesen unmittelbar zur Tat veranlasst. Zwar ist dem Vorschlag $\mathrm{zu}$ folgen, insofern er ein moralisch anstößiges Verhalten im Vorfeld für ungenügend hält. Nur durch den Verzicht auf moralisch-sittliche Erwägungen kann die Trennung von Recht und Moral strikt durchgehalten und die Grenzziehung auf rechtlich klar konturierte Kriterien gestützt werden. Das Tötungsunrecht kann jedoch darüber hinaus auch in Fällen gemindert sein, in denen der Täter sich durch die Tötung gegen einen gegenwärtigen rechtswidrigen Eingriff des Opfers in seine Rechtssphäre verteidigt, aber die Grenzen der Erforderlichkeit oder Gebotenheit des $§ 32$ StGB missachtet. Es geht also mit anderen Worten um Fälle der Unrechtsminderung durch Teilverwirklichung eines Rechtfertigungsgrundes ${ }^{275}$, bei dem es sich auch um den Notstand gemäß $\S 34$ StGB oder um das Festnahmerecht nach $\S 127$ Abs. 1 StPO handeln kann. Die eigentliche ratio hinter der vereinzelt gebliebenen Strategie der höchstrichterlichen Rechtsprechung, das Merkmal der Arglosigkeit beim Heimtückemord zu „normativieren“276, besteht gerade in der Möglichkeit, die Unrechtsminderung bei der Tatbewertung zu Gunsten des Täters anrechnen zu können. Da die herrschende Lehre den ungeschriebenen Mordunrechtsausschließungsgrund als Institut bisher nicht anerkannt hat ${ }^{277}$, wäre es angezeigt, diese Fälle in den Privilegierungstatbestand einzubeziehen.

Auffällig ist schließlich, dass die Entwurfsfassung des $§ 212$ StGB nicht die Voraussetzung des geltenden minder schweren Falls des Totschlags aufgreift,

274 Gesamtkonzeption von Deckers, Grünewald, König und Safferling, in: Abschlussbericht (Anm. 4), S. 92f.

275 So auch Grünewald (Anm. 33), S. 229; ebenso Sotelsek (Anm. 203), S. 393 ff.

276 BGHSt. 48, $207 \mathrm{ff}$.

277 Grundlegend Günther, JR 1985, 268 ff.; ihm folgend Morris, Die normative Restriktion des Heimtückebegriffs auf Basis der Teilverwirklichung von Rechtfertigungsgründen, 2010, S. 150 ff., $155 \mathrm{ff}$. 
dass der Täter durch eine ihm oder einem Angehörigen zugefügte Misshandlung oder schwere Beleidigung zum Zorn gereizt und hierdurch auf der Stelle zur Tat hingerissen worden sein muss. Der Verzicht auf den sthenischen Affekt ist kein Zufall: Denn nach Ansicht von Grünewald, auf deren Konzeption der Gesetzgebungsvorschlag maßgeblich beruht, soll der Zorn des Täters für die Unrechtsminderung irrelevant $\operatorname{sein}^{278}$. In normativer Hinsicht nennt sie zunächst als ersten Grund den klassischen bzw. strengen, von Köhler aufgegriffenen Affektbegriff ${ }^{279}$, der auf der Vorstellung fußt, dass eine aus Überlegung begangene Tat die Schuld steigere, die Überlegung sich in diesem Sinne als Vollform der Schuld erweise ${ }^{280}$. Dagegen ist allerdings einzuwenden, dass die Anerkennung einer schuldmindernden Wirkung eines Affekts keinesfalls eine Schuldkonzeption impliziert, die Schuld als steigerungsfähige Kategorie begreift. Die schuldmindernde Berücksichtigung von Gemütsbewegungen lässt sich durchaus mit dem Standpunkt vereinbaren, dass die Schuldzurechnung nur gemindert, nicht aber gesteigert werden kann. Zutreffend ist hingegen der Einwand, dass der Affekt nicht die Unrechtseinsicht betrifft, er kann aber - wie Grünewald selbst konzediert - die Steuerungsfähigkeit beeinträchtigen ${ }^{281}$. Als zweiten Grund für die Ausblendung des Affekts nennt sie den Umstand, dass sich Affekt und Motivzusammenhang nicht mit hinreichender Verlässlichkeit empirisch ermitteln ließen ${ }^{282}$. Diese Schwierigkeiten sind in der Tat nicht von der Hand $\mathrm{zu}$ weisen. Sie sind aber unvermeidbar mit der Geltung des Schuldprinzips verbunden. Dieses zwingt dazu, die psychische Befindlichkeit des Täters zu rekonstruieren. Auch bei den $\S \S 20,21$ StGB und bei $\S 33$ StGB ist man mit derselben Schwierigkeit konfrontiert. Es stellt sich zudem die Frage, ob die postulierte Minderung des Tötungsunrechts aufgrund der Anlasstat überhaupt ohne Berücksichtigung des sthenischen Affekts erklärbar ist. Denn durch die Tötung werden Rechtsgüter des Täters weder verteidigt noch vor einer Verletzung bewahrt ${ }^{283}$. Auch geht der Täter nicht von einer derartigen Wirkung aus. Blendet man den motivationspsychologischen Zusammenhang aus, lässt sich zudem auch kein Grund mehr für die zeitliche Eingrenzung der Reaktion auf die Anlasstat anführen.

Dabei ist durchaus die Ansicht vorzugswürdig, dass aufgrund der Provokation des Opfers nicht nur die Schuld, sondern schon das Unrecht der Tat gemin-

278 Grünewald (Anm. 33), S. 321 ff.; dies., in: Abschlussbericht (Anm. 4), S. 477, 480, 506, 510.

279 Köhler, in: Klesczewski (Hrsg.), Affekt und Strafrecht, 2004, S. 9 ff.

280 Vgl. Köhler, GA 1980, 121, 130, 134.

281 Grünewald (Anm. 33), S. 199ff., 342, 358.

282 Grünewald (Anm. 33), S. 263, 340, $344 \mathrm{ff}$.

283 Ebenso ablehnend Günther, JR 1985, 268, 271. 
dert ist ${ }^{284}$. Die Erklärung der von $\S 213$ StGB angeordneten Strafmilderung von Teilen der Literatur mit einer bloßen Schuldminderung unter Verweis auf den sthenischen Affekt ${ }^{285}$ ist schon deswegen unzulänglich, weil sie völlig unberücksichtigt lässt, dass der Zorn auf der Provokation des Opfers beruhen muss. Der erhebliche Affekt mindert die Schuld aufgrund der Einschränkung der Steuerungsfähigkeit grundsätzlich ganz unabhängig von seiner Entstehungsursache. Insoweit stehen durch die $\S \S 20,21$ StGB schon allgemeine Regelungen zur Verfügung. Zu klären ist allerdings, worauf die Unrechtsminderung beruht. Teilweise begründet man diese damit, dass durch die Provokation der Anspruch auf strafrechtlichen Schutz verringert $\operatorname{sei}^{286}$. Es fehlt freilich die Nennung eines Grunds dafür, warum der Anspruch auf strafrechtlichen Schutz partiell erloschen ist und warum dies auch bei abgeschlossener Vortat gilt. Die Annahme einer Art Verwirkung wäre verfassungsrechtlich bedenklich ${ }^{287}$. Ebenso wenig ist die Ansicht überzeugend, dass die Provokation das Handlungsunrecht reduziere ${ }^{288}$. Tragfähiger ist die Argumentation, dass das Opfer aufgrund der Provokation für den Angriff auf sein Leben mitverantwortlich sei und sich daher die Tat selbst zuzuschreiben habe ${ }^{289}$. Die Begründung bedarf allerdings noch der Präzisierung: Die Mitverantwortlichkeit des Opfers beruht darauf, dass es durch seine Anlasstat den sthenischen Affekt beim Täter und damit die Schuldminderung in vorwerfbarer Weise ausgelöst hat. In dem Maße, in dem die Schuld des Täters durch die Provokation gemindert ist, kann dem Opfer die Fremdtötung als Selbstschädigung zugerechnet werden ${ }^{290}$. Eine Selbstschädigung schließt jedoch das Unrecht aus. Und umgekehrt: Würde die Anlasstat keinen Zorn in schuldmindernder Intensität hervorrufen, bliebe der Täter für die Tötungstat ungeachtet der Provokation voll verantwortlich und es gäbe daher keinen Grund, das Opfer für diese

284 Kern, ZStW 64 (1952), S. 255, 286; ebenso Heine (Anm. 58), S. 269; Hillenkamp, Vorsatztat und Opferverhalten, 1981, S. 272f.; Küper, JZ 1968, 651, 657; Mitsch, JuS 1996, 26, 29; Müssig (Anm. 14), S. 317; anders noch Haas, Festschrift für Krey, S. 117, 138.

285 Schneider, in: MK (Anm. 74), § 213 Rdn. 5; Sinn, in: SK StGB (Anm. 54), Vor § 213 Rdn. 1; vgl. Eser/Sternberg-Lieben, in: Schönke/Schröder (Anm. 43), § 213 Rdn. 1, die allerdings auch eine Unrechtsminderung in Erwägung ziehen.

286 Kern, ZStW 64 (1952), S. 255, 286; Sotelsek (Anm. 203), S. 435.

287 Sotelsek (Anm. 203), S. 440.

288 So aber Heine (Anm. 58), S. 269.

289 Mitsch, JuS 1996, 26, 29; Grünewald (Anm. 33), S. 223, 228 ff.; vgl. auch Neumann, in: NK StGB (Anm. 43), § 213 Rdn. 6, der ebenfalls eine Mitverantwortlichkeit des Opfers postuliert, aber sowohl eine Unrechts- wie auch eine Schuldminderung in Abrede stellt, ohne allerdings zu erklären, warum gleichwohl die Strafe gemindert werden kann.

290 Es handelt sich um einen Sonderfall der Selbstschädigung, weil im Normalfall das selbstschädigende Verhalten des Opfers dem Verhalten des Täters zeitlich nachfolgt. 
Tat für mitverantwortlich zu erklären ${ }^{291}$. Daraus erhellt: Eine Minderung des Unrechts lässt sich nur auf den Affekt des Täters stützen. Nur der Affekt macht auch erklärlich, warum es einer gravierenden Anlasstat und es eines engeren zeitlichen Zusammenhangs bedarf. Es sind diejenigen Voraussetzungen, kraft derer mit einer affektbedingten Reaktion des Täters zu rechnen und daher eine Zurechnung geboten ist.

Würde man den Mord vom Totschlag durch den Umstand abgrenzen, dass das Opfer durch sein Verhalten Anlass zur Tat gegeben hat, würde man - sieht man von der Fallkonstellation der Teilverwirklichung eines Rechtfertigungsgrundes ab wieder historisch an die Tatbilder der Peinlichen Gerichtsordnung anknüpfen. Dies gilt zumindest dann, wenn eine bestimmte Interpretation des Art. 137 PGO zugrunde gelegt wird. Gemäß Art. 137 PGO war ein „fürsetzlicher, mutwilliger mörder“ zu rädern, während derjenige der „eyn todtschlag, aus gecheyt vnd zorn“ begangen hatte, mit dem Schwert zu bestrafen war. Nicht geklärt ist zunächst, ob „fürsetzlich“ mit „Vorbedacht“ oder „Überlegung“ zu übersetzen ist oder mit „Vorsatz“ bzw. „Absicht“. Entscheidend ist jedoch der Streit, ob das Prädikat „mutwillig“ eine eigenständige Bedeutung besaß. Bejahendenfalls hätte es Tötungen sine causa - also ohne „genugsam Ursach“ (Art. 148 PGO) - erfasst, bei denen das Opfer dem Täter keinen Anlass zur Tat gegeben hatte ${ }^{292}$. Der sthenische Affekt wäre also von vornherein als ein vom Opfer provozierter Affekt aufzufassen. Das spätere gemeine Recht ist dann eigene Wege gegangen, sofern der Affekt von seiner Entstehungsursache abgekoppelt wurde und die Lehre vom dolus directus bzw. indirectus auf die Bestimmung der Rechtsfolge Einfluss gewann - ein Einfluss, der sich im Preußischen Allgemeinen Landrecht niedergeschlagen hat ${ }^{293}$. Erst Feuerbach hat in Anknüpfung an die Peinliche Gerichtsordnung die durch das Opfer veranlasste Tat wiederentdeckt und in Art. 152 des Bayerischen Strafgesetzbuchs als Milderungsgrund des in Art. 151 geregelten einfachen Totschlags ausgestaltet. Art. 151 sah vor, dass derjenige, der ohne Überlegung und Vorbedacht in aufwallender Hitze des Zorns eine lebensgefährliche Handlung wider den anderen beschließt und ausführt, bei erfolgtem Tode mit Zuchthausstrafe auf unbestimmte Zeit zu bestrafen sei. Hingegen sollte gemäß Art. 146, der „von dem Mord überhaupt“ handelte, derjenige, der die von ihm verursachte Entleibung mit Vorbedacht beschlossen oder mit Überlegung ausgeführt hat, mit dem Tode bestraft werden. Art. 147 drohte bei Mordqualifikationen sogar verschärfte Todesstrafe als Rechtsfolge an. Das Modell einer Dreistufung - Tötung ohne Affekt, Tötung im

291 Vgl. aber Sotelsek (Anm. 203), S. 435f., der ganz offensichtlich Unrechts- und Schuldminderung als separate Aspekte begreift.

292 Siehe ausführlich dazu Grünewald (Anm. 33), S. 65 ff.; vgl. auch Müssig (Anm. 14), S. 29.

293 Müssig (Anm. 14), S. $30 \mathrm{ff}$. 
Affekt und Tötung mit einem durch das Opfer veranlassten Affekt - hat dann wiederum das Preußische Strafgesetzbuch von 1851 und das Reichsstrafgesetzbuch von 1871 beeinflusst. Es ist diese Dreistufung, die zur Ausgestaltung des Mordes als Qualifikationstatbestand geführt hat.

\section{Schlussbemerkung}

Summa summarum muss leider festgehalten werden, dass die Beschlüsse der Expertengruppe zumeist nicht überzeugen können. Wegweisend ist lediglich der Vorschlag, künftig die lebenslange Freiheitsstrafe nicht mehr absolut anzudrohen. Allein um dieses Vorschlags willen hätte es der Einsetzung einer Expertengruppe jedoch nicht bedurft. Natürlich ist es in der Rechtswissenschaft zumeist vertretbar, anderer Auffassung zu sein. Die Unschärfe spielt in unserer Zunft eine ungleich größere Rolle als in den Naturwissenschaften. Anders wäre die Meinungsvielfalt kaum erklärbar. Dies gilt ohne Zweifel auch für denkbare Neugestaltungen der Tötungsdelikte. Aber was man zumindest verlangen darf, ist die Bereitschaft, sich ernsthaft und ergebnisoffen mit den Argumenten der Gegenansicht auseinanderzusetzen. Und dies ist die eigentliche Enttäuschung: Man findet in den umfangreichen Begründungen und Ausführungen kein Erwägen und Abwägen der Argumente, auf die sich vornehmlich die Anhänger des Privilegierungsmodells berufen. Diese Argumente stützen die vielfach geteilten Bedenken gegen die gegenwärtige Fassung des Mordtatbestandes bzw. der Tötungsdelikte. Umso mehr wäre zu erwarten gewesen, dass die Empfehlungen der Expertengruppe auf einer intensiven Erörterung eben dieser Bedenken beruhen. Inzwischen hat offenbar das Bundesministerium für Justiz und Verbraucherschutz einen Referentenentwurf vorgelegt, der den Mord als Qualifikationstatbestand ausgestaltet, an den Mordmerkmalen mit gewissen Modifikationen festhält und die absolute Androhung der lebenslangen Freiheitsstrafe durch Einfügung eines zweiten Absatzes, der schuldmindernde Faktoren berücksichtigt, beseitigt ${ }^{294}$. Dieser Referentenentwurf scheint jedoch am Widerstand der CDU/CSU-Fraktion gescheitert zu sein. Damit wäre der Reformprozess beendet, bevor er richtig begonnen hat. Und es steht zu befürchten, dass die deutsche Strafrechtspflege auf lange Zeit mit der gegenwärtigen Gesetzeslage wird leben müssen!

294 Siehe dazu Wilmes, AnwBl 2016, $494 \mathrm{ff}$. 